\title{
Neuromarketing: The Cognitive Approaches to Consumer Behavior
}

\author{
Leyla Bayan ${ }^{1,2 *}$, Fatemeh Alipour ${ }^{1}$, Pirhossein Kolivand ${ }^{1,3}$, Samaneh Sadat Dastgheib \\ ${ }^{1}$ Shefa Neuroscience Research Center, Khatam Alanbia Hospital, Tehran, Iran. \\ ${ }^{2}$ Faculty of Management and Accounting, Qazvin Branch, Islamic Azad University, Qazvin, Iran. \\ ${ }^{3}$ Public Administration Department, Higher Education Center, Payame Noor University, Tehran, Iran.
}

\section{A BSTRACT}

Introduction: Neuromarketing is an interdisciplinary field that is rapidly emerging in the world of consumer cognition research. Furthermore, it is an innovative field of marketing research which challenges the classic marketing model to improve our understanding of the processes associated with purchasing behavior. Neuromarketing is investigating the manner that consumers make the decision to purchase. Based on the neuromarketing concept of decision processing, consumer buying decisions rely on bi-systemic approaches. System 1 is based on fast automatic operations; in contrast, decisions driven by System 2 are deliberate, conscious reasoning, and slow. In cognition of the consumer behavior, these processes guide everyday purchasing decisions. Furthermore, neuromarketing is built on the top of at least three basic science fields, including neuroscience, behavioral economics, and social psychology. The aim of this review was to investigate the different aspects of neuroscience involved in neuromarketing. The signals from the human body and brain, are important for understanding the origins and operations of neuromarketing measures. Body measures are contained the facial expressions, eye movements, eye blink, startle reflex, behavioral responses, electrodermal activity, heart rate, blood pressure, pupil dilation, and respiration. The human brain signals are captured by the blood oxygenation, positron emissions, electrical fields, and magnetic fields. Conclusion: Understanding the basic functions of human brain is crucial in investigation of consumers' purchasing behaviors.

\section{Key words:}

1. Marketing

2. Neurosciences

3. Decision Making

4. Brain

5. Neuroimaging

* Corresponding Author: Leyla Bayan

E-mail:Leila.Bayan@gmail.com 


\title{
بازاريابى عصبى: رويكردهاى شناختى در خصوص رفتار مصرف كننده
}

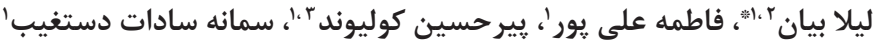 \\ 'مركز تحقيقات علوم اعصاب شفا، بيمارستان خاتمالانبياء، تهران، ايران.

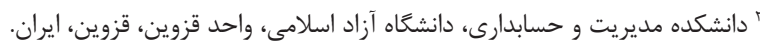

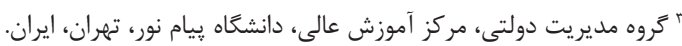

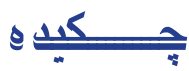

مقدمه: بازاريابى عصبى يك علم ميان رشتهاى است كه به سرعت در تحقيقات شناخت مصرف كننده

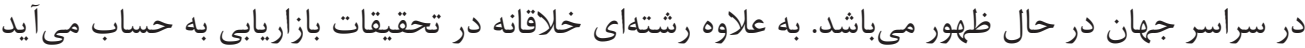

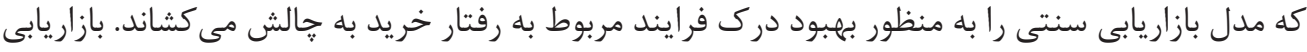

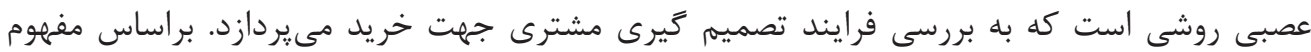

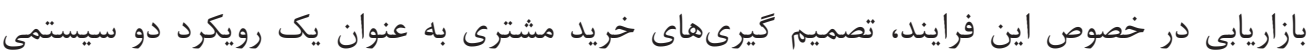

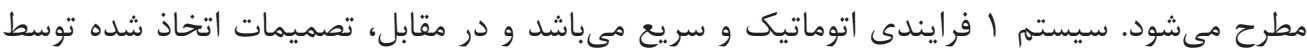

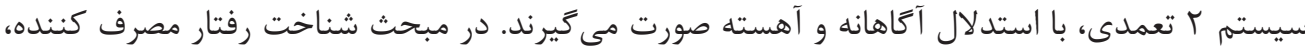

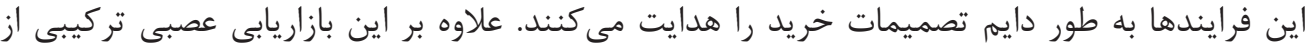

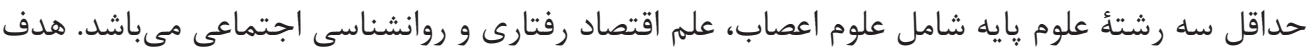

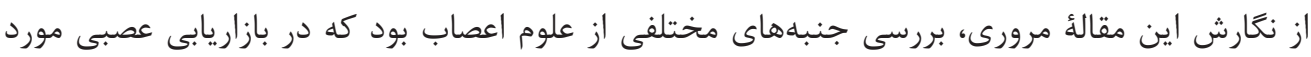

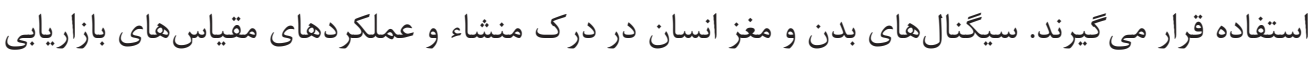

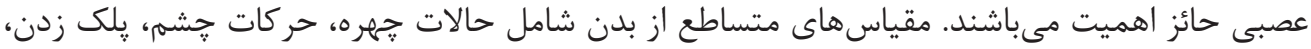

كليد وازهها:

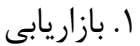

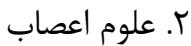

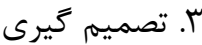
ث

ه. تصويربردارى عصبى

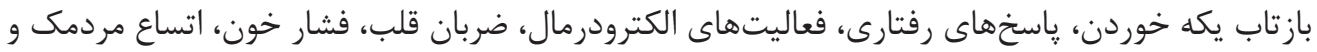

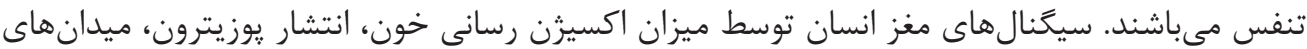

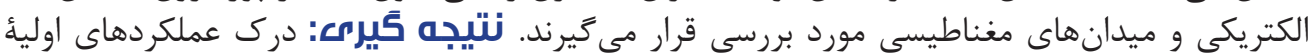

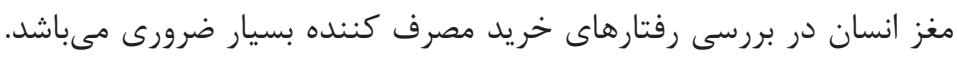

" نويسنده مسئول: ليلا بيان آدرس الكترونيكى: Leila.Bayan@gmail.com 


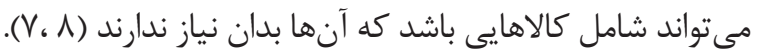

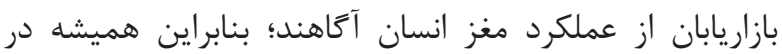

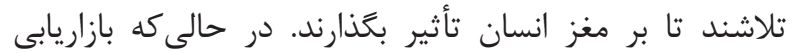

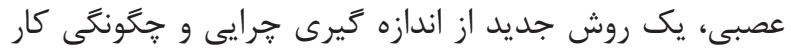

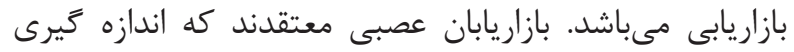

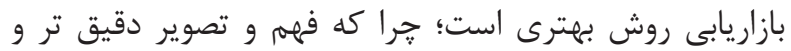

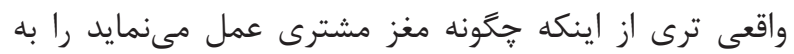

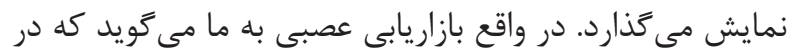

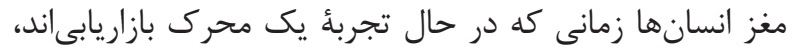

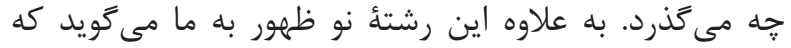

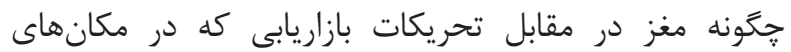

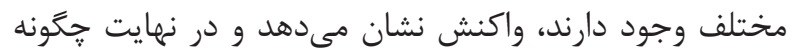

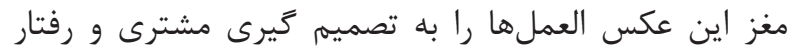

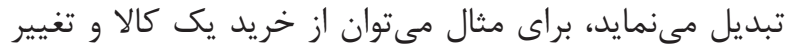

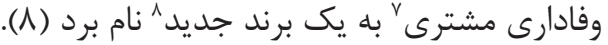
بازاريابى عصبى براساس سه رشتأ اصلى علوم اعصاب، علم إسلم

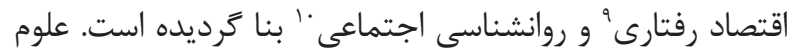

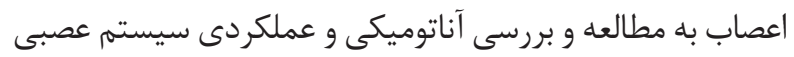

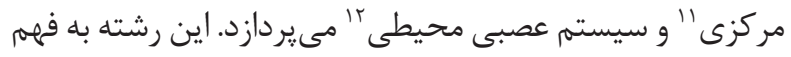

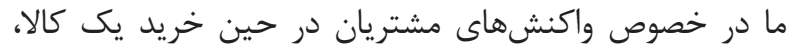

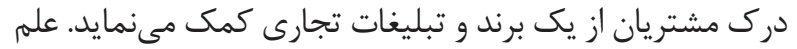

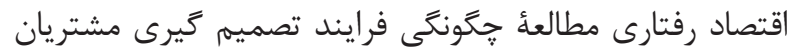

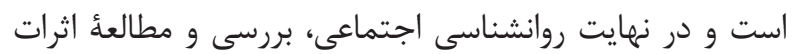

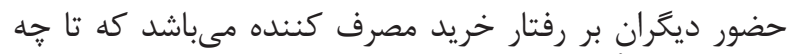

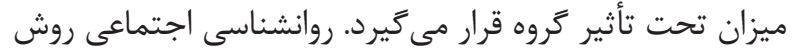

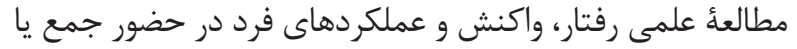

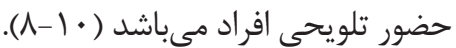

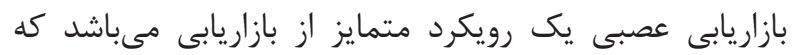

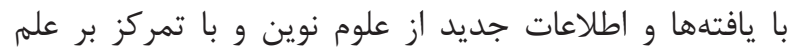

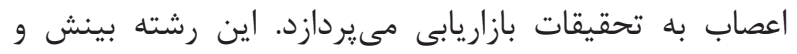

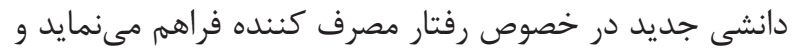

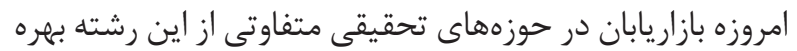

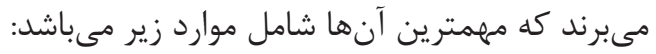

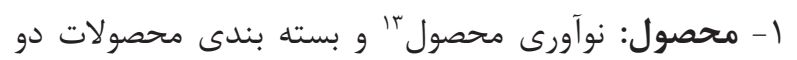

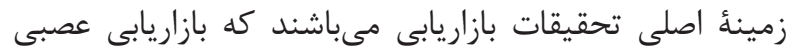

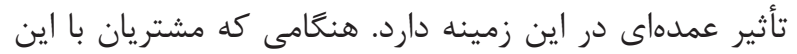

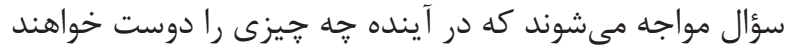

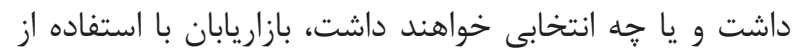

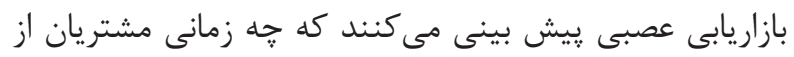

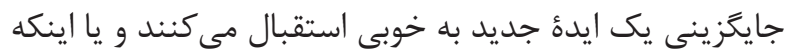

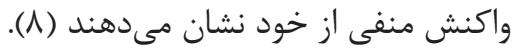

ץ- برند: شناخت و درك برندهاى محصولات و مقولئ برند شناسى كإي

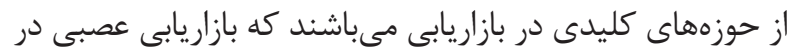

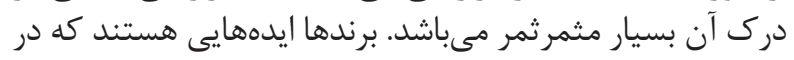

${ }^{1}$ Neuromarketing

${ }^{2}$ Consumer behavior

${ }^{3}$ Neuroscience

${ }^{4}$ Ale Smidts

${ }^{5}$ Pushing the buy button

${ }^{6}$ Applied social psychology

${ }^{7}$ Consumer loyalty

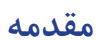

ظهور بازاريابى عصبى

بازاريابى عصبى' يك رشته نوظهور است كه مطالعات رفتار

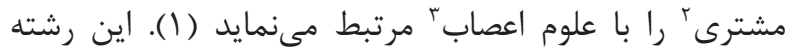

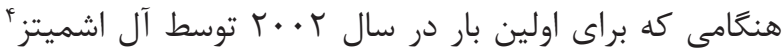

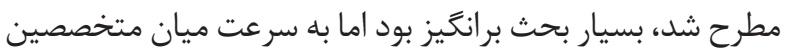

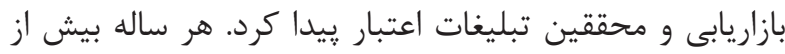

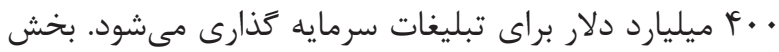

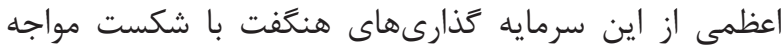

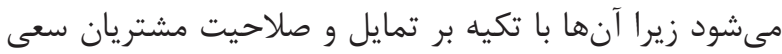

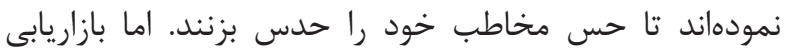

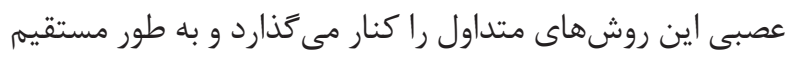

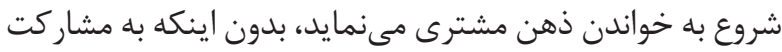

شناختى و آكاهانه وى نياز باشد (بـ م-1).

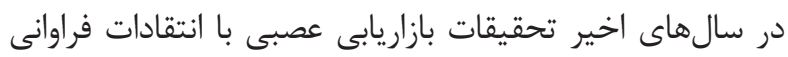

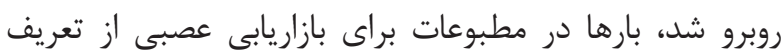

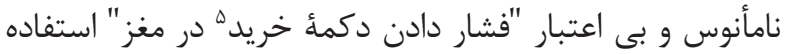

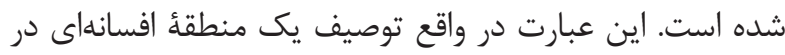

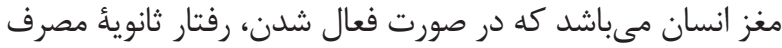

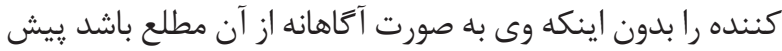

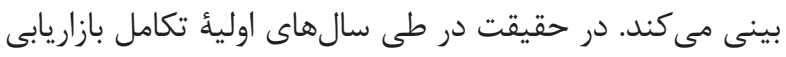

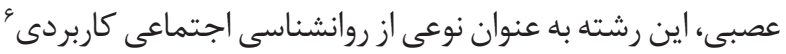

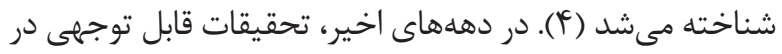

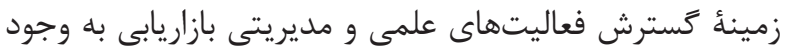

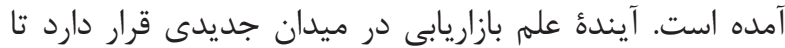

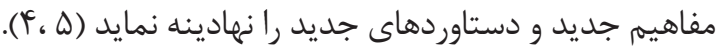

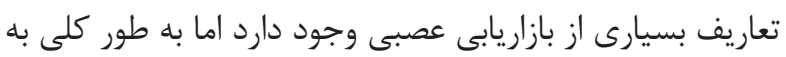

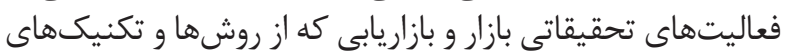

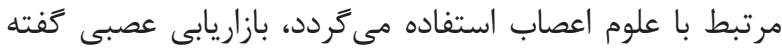

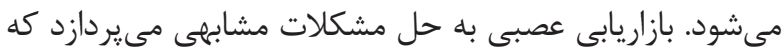

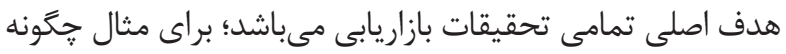

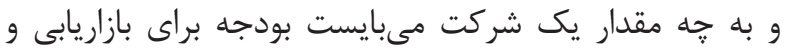

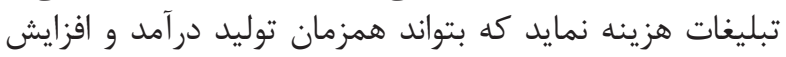
سود نيز براى سرمايه كذاران داشته باشد (4، هاند).

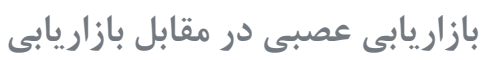

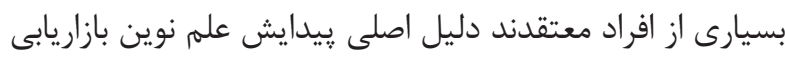

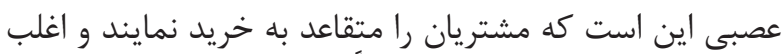

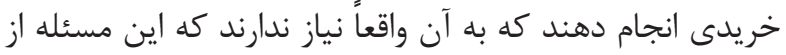

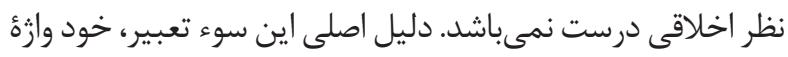

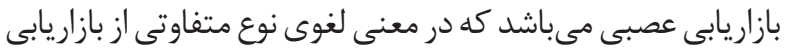

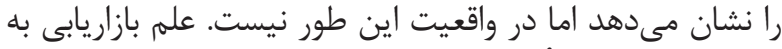

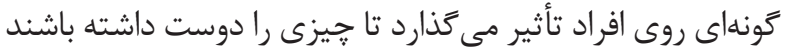
و در نهايت منجر به خريد آن شود. اين آنداردي اقلام خريدارى شده

${ }^{8}$ New brand

${ }^{9}$ Behavioral economics

${ }^{10}$ Social psychology

${ }^{11}$ Central nervous system

${ }^{12}$ Peripheral nervous system

${ }^{13}$ Product 
يريسى" آغاز نمود. اين تحقيق براى سالهاى متوالى در

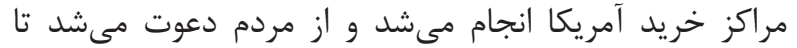

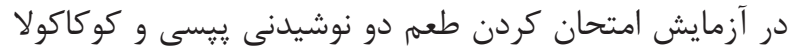

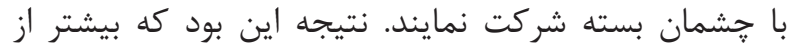

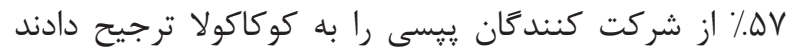
(19)

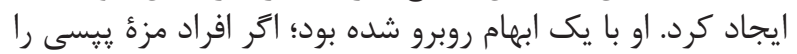

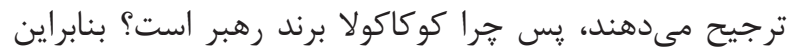

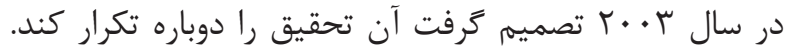

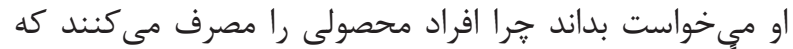

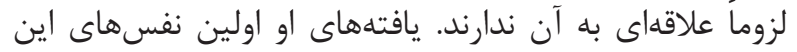

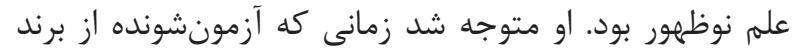

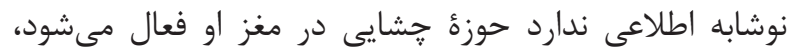

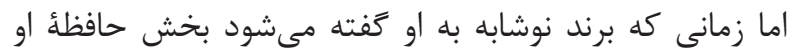

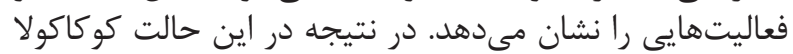

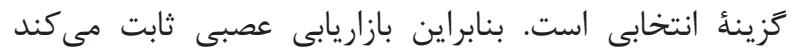

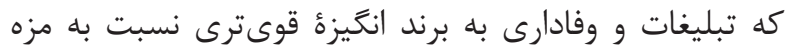

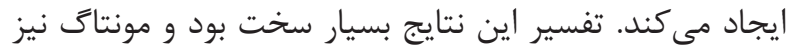

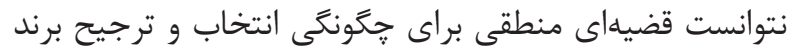

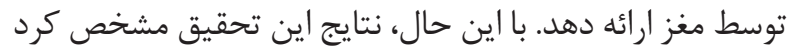

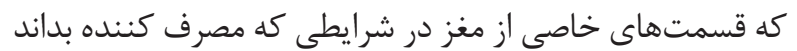

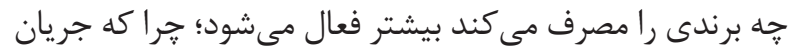

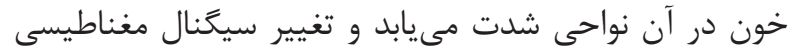

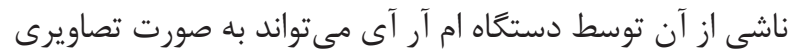

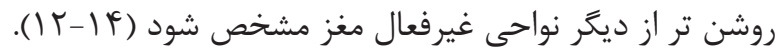

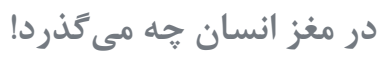

از آنجايى كه مطالعة بيولوزى و فيزيكى مغز مهمترين راه براى

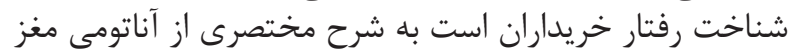

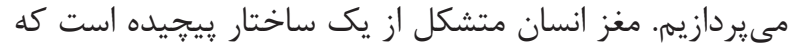

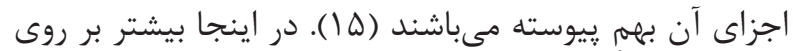

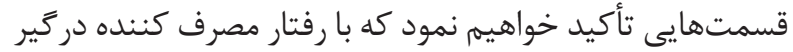

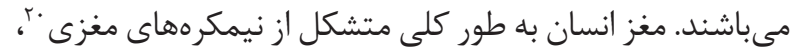

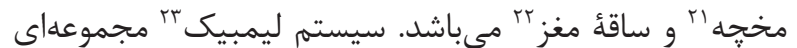

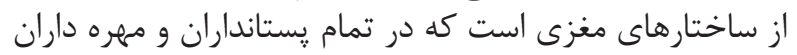

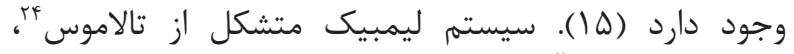

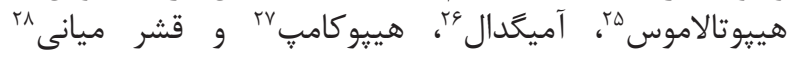
مىباشد (تصوير ().

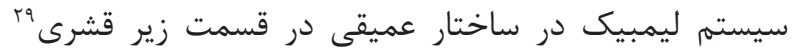

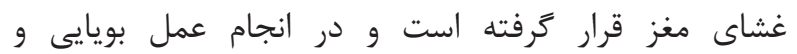

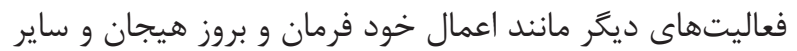

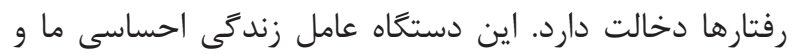

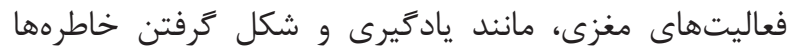

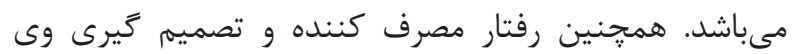

\footnotetext{
${ }^{14}$ Shopping marketing

${ }^{15}$ McClure

${ }^{16}$ Mental preferences

${ }^{17}$ Behavior preferences

${ }^{18}$ Functional magnetic resonance imaging (fMRI)

${ }^{19}$ Montague

${ }^{20}$ Brain hemispheres

${ }^{21}$ Cerebellum
}

ذهن وجود دارند و زمانى كه با ساير ايدها در ذهن ارتباط ريدا

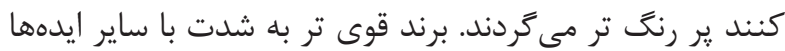

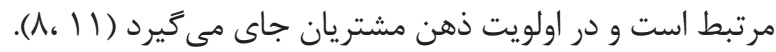
" - تبليغات: تحقيقات تبليغاتى يكى از عوامل فعال و مهلهم

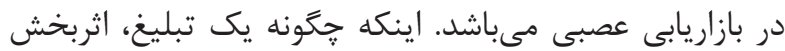

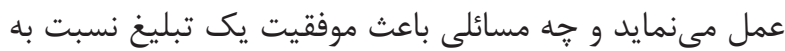

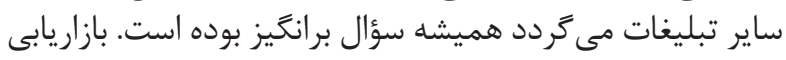

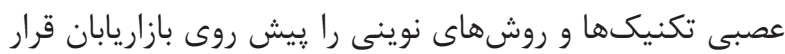

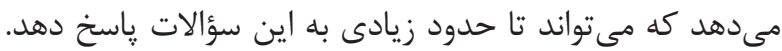

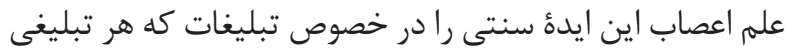

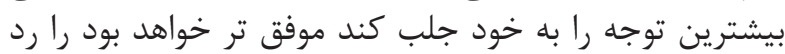

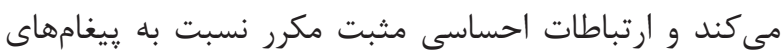

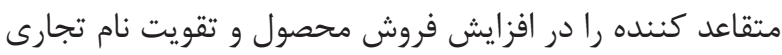

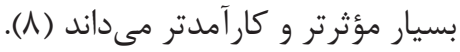

F - خريد: بازاريابى خريد" نيز از مباحثى است كه بازاريابى

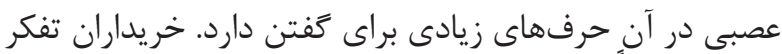

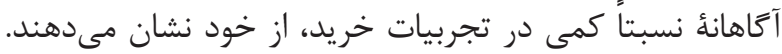

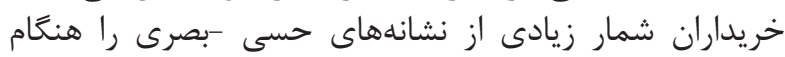

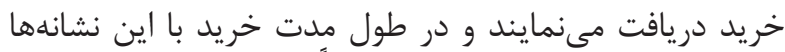

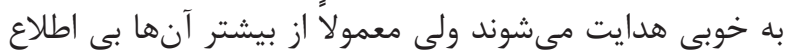

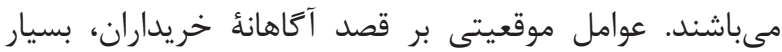

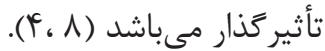

ه- آنلاين : در دنياى آنلاين، تبليغات و خريد رابطة تنكاتنكَى

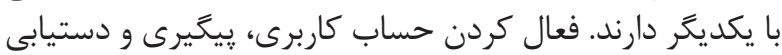

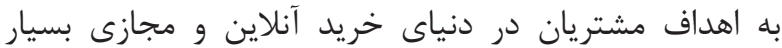

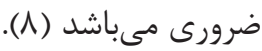

ترجيحات ذهنى و ترجيحات رفتارى

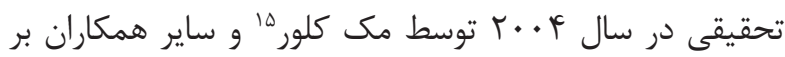

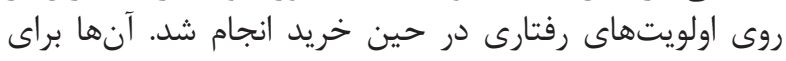

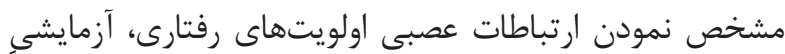

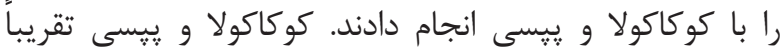

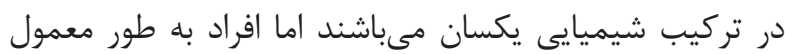

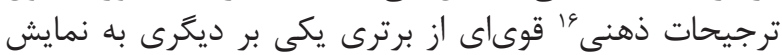

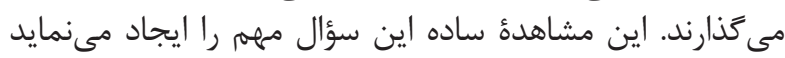

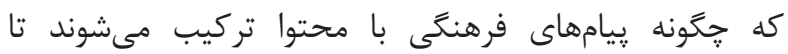

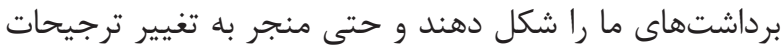

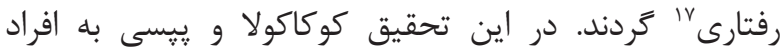
مشخصى جهت آزمايش داده شد تا رفتار آنها را را در حالى حالى كه

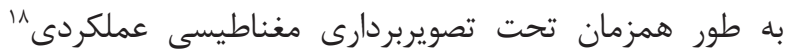

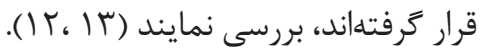

در سال 19VD يֶسى يك كميين بازاريابى با عنوان "جالش

\footnotetext{
${ }^{22}$ Brain stem

${ }^{23}$ Limbic system

${ }^{24}$ Thalamus

${ }^{25}$ Hypothalamus

${ }^{26}$ Amygdala

${ }^{27}$ Hippocampus

${ }^{28}$ Middle layer

${ }^{29}$ Sub cortical
} 


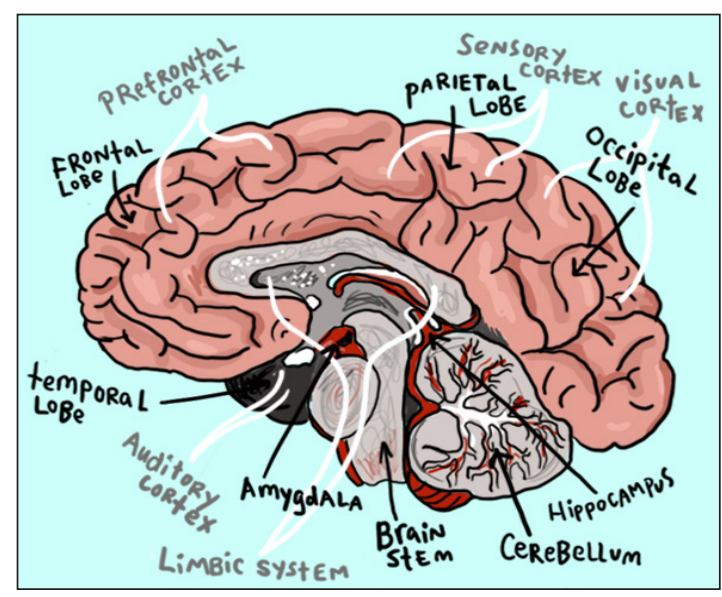

تصوير 1- مناطق مختلف مغز انسان را نشان مىدهد (19).

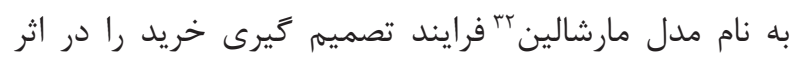

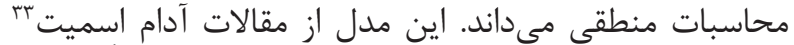

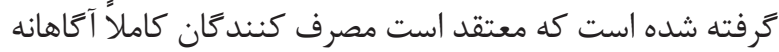

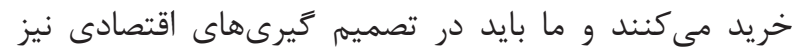

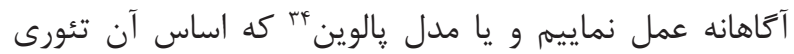

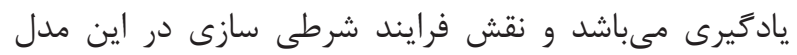

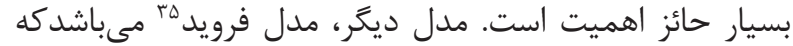

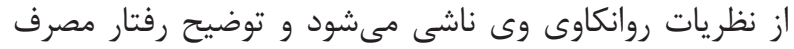

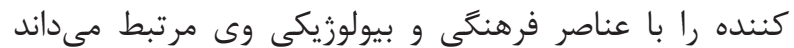

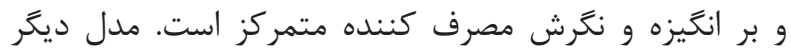

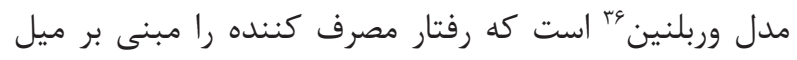

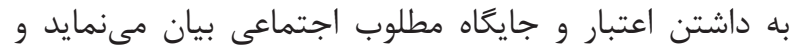

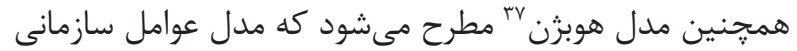

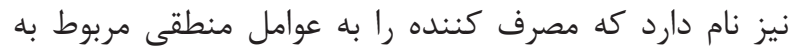

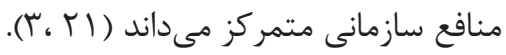

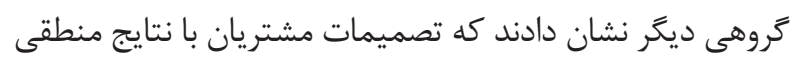

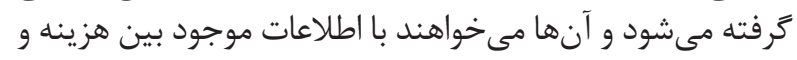

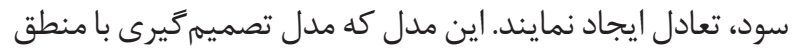

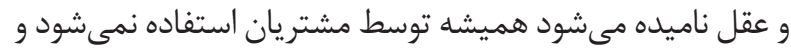

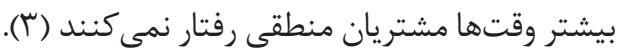

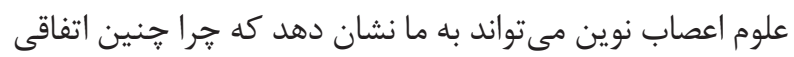

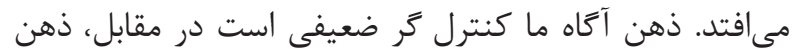

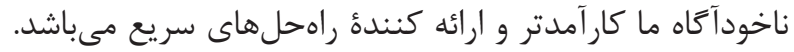

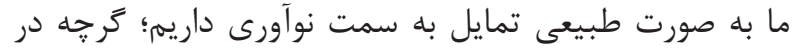

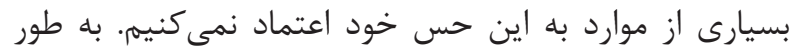

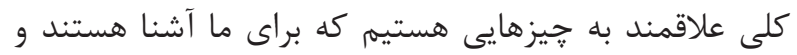

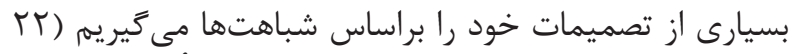

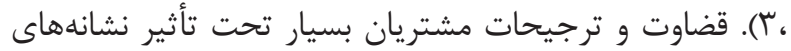

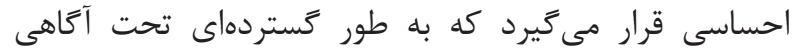

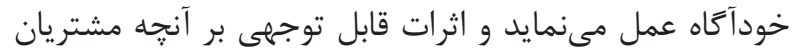

\footnotetext{
${ }^{30}$ Frontal lobs

${ }^{31}$ Prefrontal cortex

${ }^{32}$ Marshallian model

${ }^{33}$ Adam smith
}

ارتباط نزديكى با اين سيستم مغزى دارد. درك كامل عملكرد

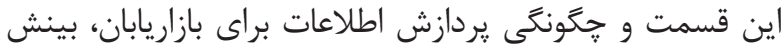

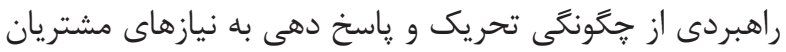

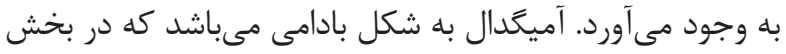

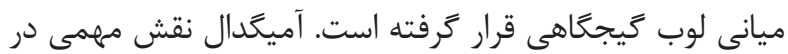

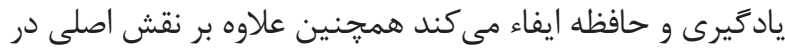

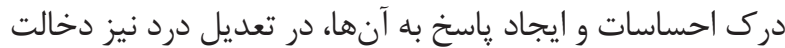

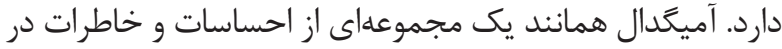

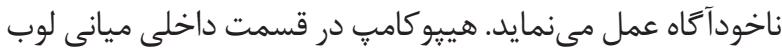

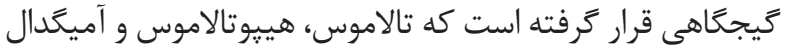

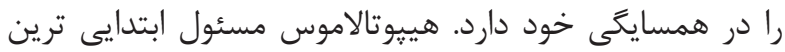

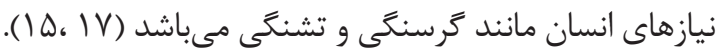

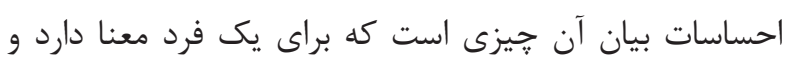

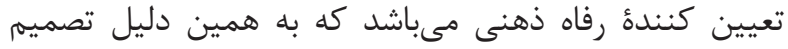

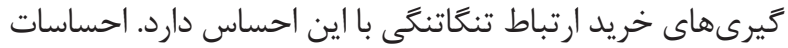

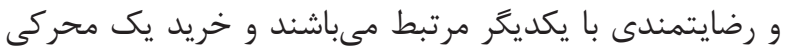

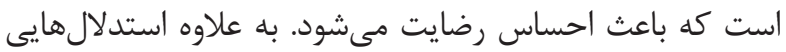

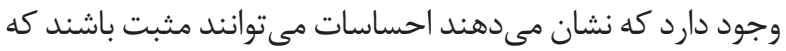

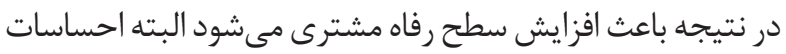

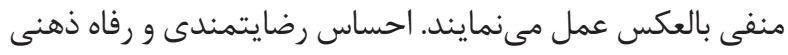

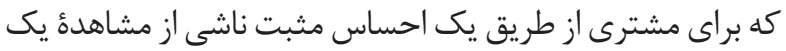

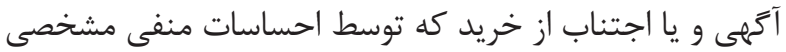

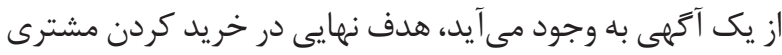

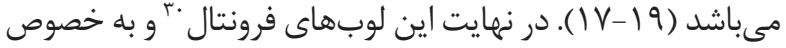

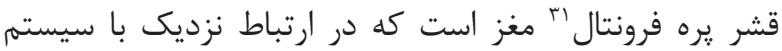

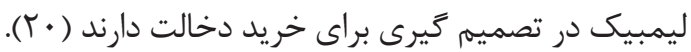

$$
\text { قدرت تصميم كيرى خريد }
$$

تصميم گيرى يك فرايند يُيجيده و رمزدار است. تاكنون

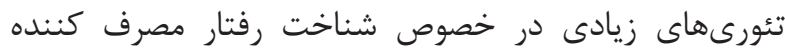
مطرح شده است؛ براى مثال در يكى از معروف ترين اين مدلها

\footnotetext{
${ }^{34}$ Palovian model

${ }^{35}$ Freudian model

${ }^{36}$ Verblenian model

${ }^{37}$ Hobbesian model
} 
كانمن از سيستم ا به عنوان سيسته بصرى نام برده است؛ در

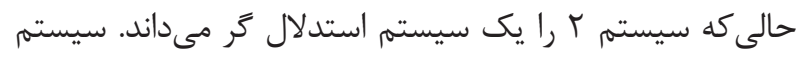

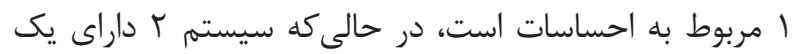

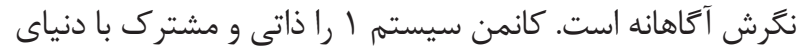

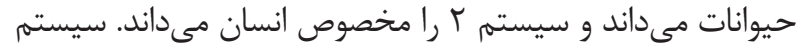

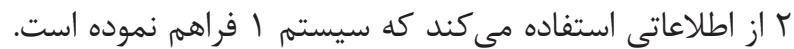

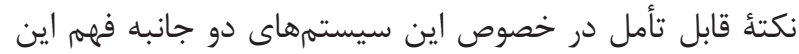

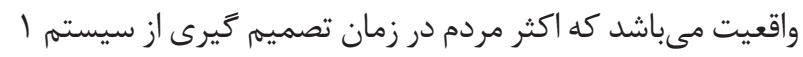

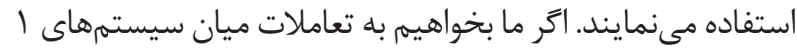

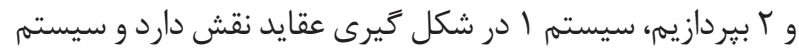

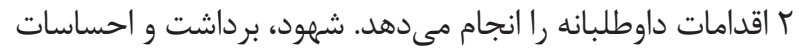

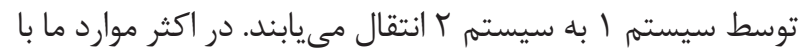

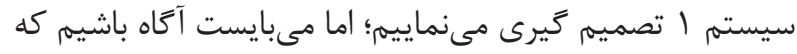
اشتباهات در سيستم ا بيشتر از سيستم ك مى مياشد.

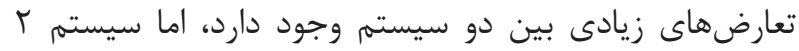

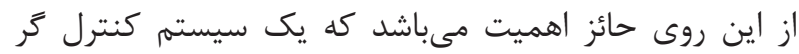

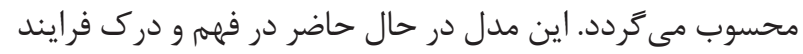

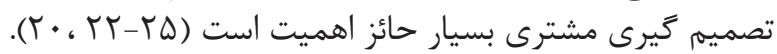
مقياسهاى اندازه َّيرى در بازاريابى عصبى بـى به منظور درك بهتر از مقياسهاى اندازه گيرى در اين زمينه،

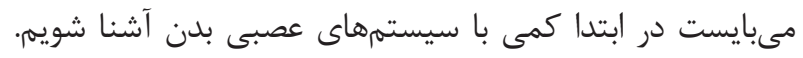

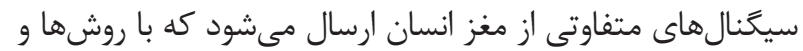

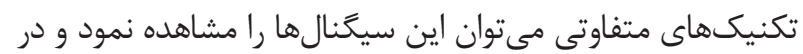

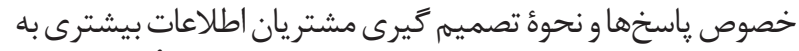

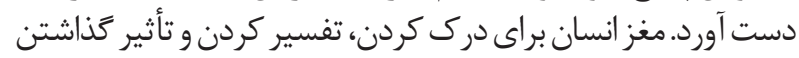

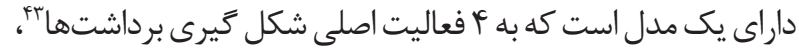

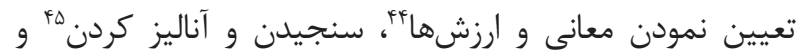

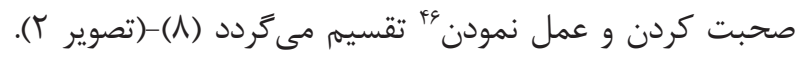

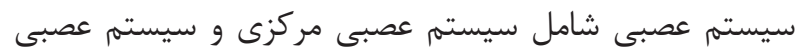

به آن توجه مىنمايند و آنجه به خاطر مىسيارند، دارد. انخيزه

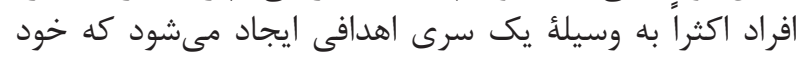

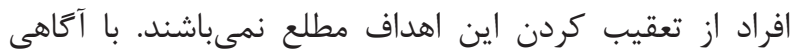

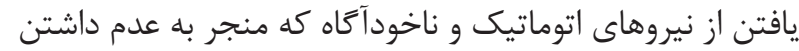

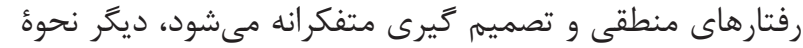

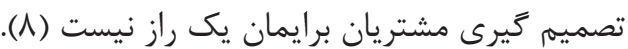

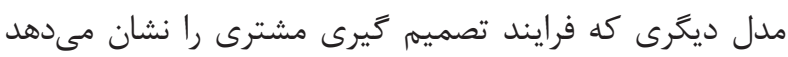

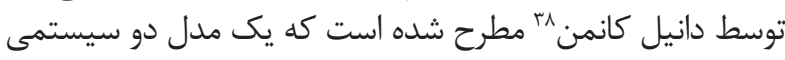

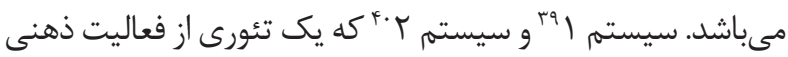

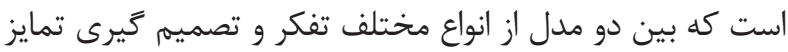

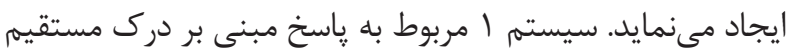

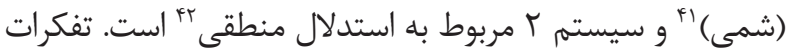

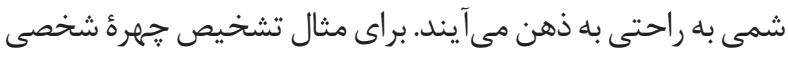

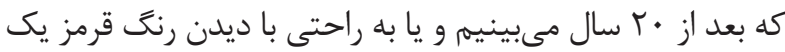

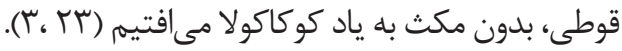

سيستم 1 داراى يك مفهوم مهمم در تصميم كيرى مىباشد؛ اما

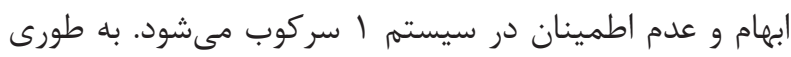

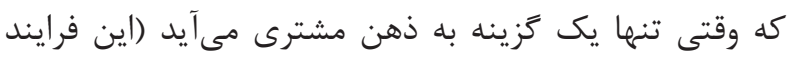

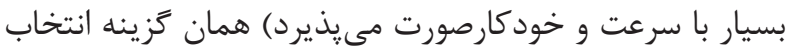

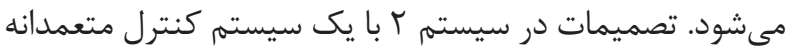

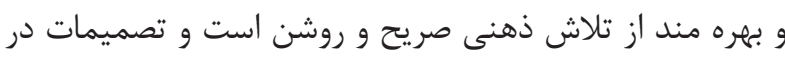

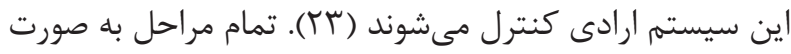

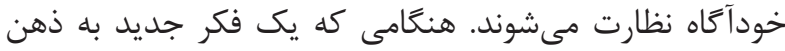

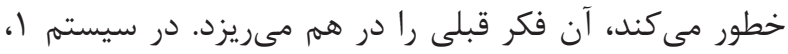

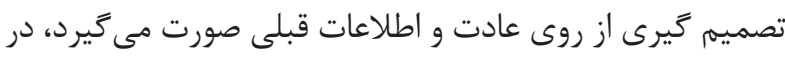

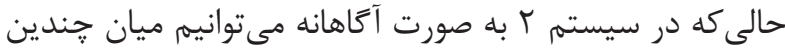

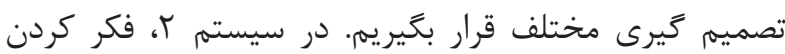

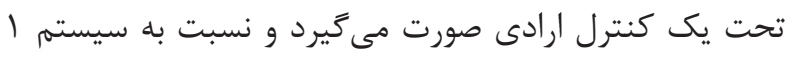

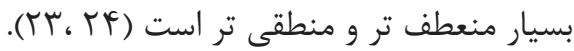

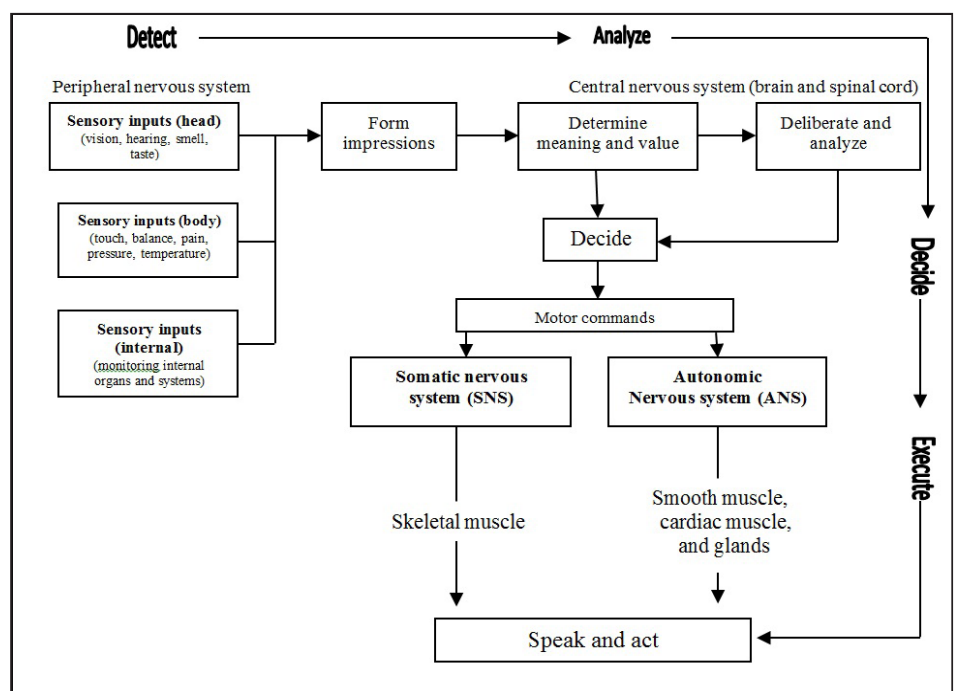

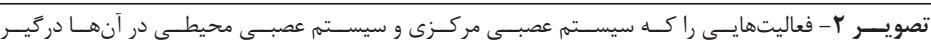

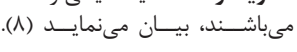

${ }^{38}$ Daniel Kahneman

${ }^{39}$ System 1

${ }^{40}$ System 2

${ }^{41}$ Intuitive response

${ }^{42}$ Logical reasoning
${ }^{43}$ Forming impressions

${ }^{44}$ Determining meanings and values

${ }^{45}$ Deliberating and analyzing

${ }^{46}$ Speaking and acting 
به فعاليتهاى مغز يى ببريم كه به جاه ميزان اكسيرن و قند را به

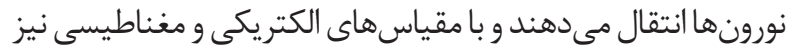

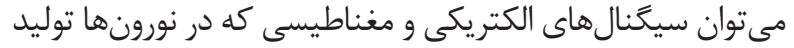
مىشوند را اندازه كيرى كرد (^). الف - اندازه كيرى سيخَنال هاى توليد شده از بدن سيخَال هاى توليد شده از بدن مى تواند شامل حر كات آشكارى

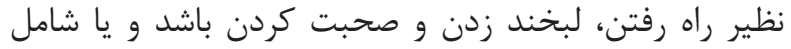

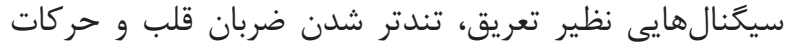

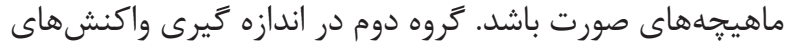

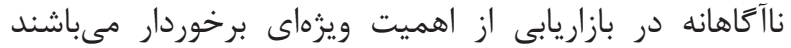

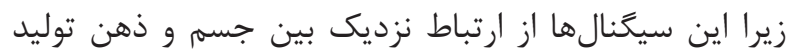

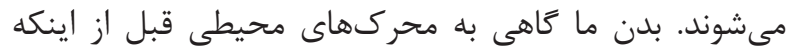

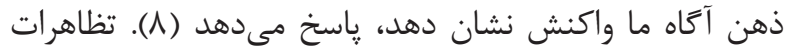

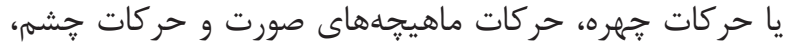

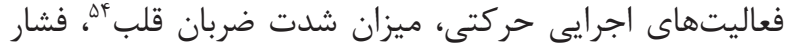

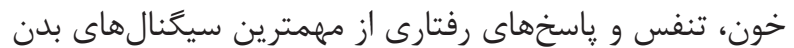

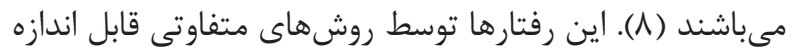

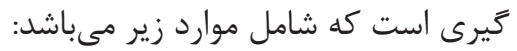

1- روش الكتروميوكرافى (نوار عصب و عضله)

جارلز داروينه در تحقيقات خود نشان داد كه برخى از

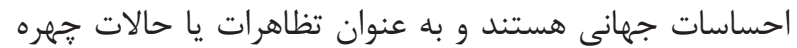

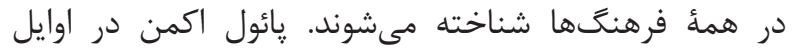

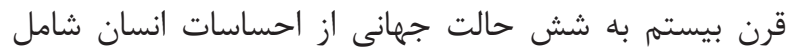

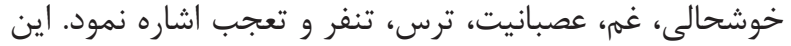

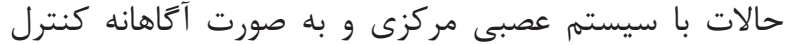

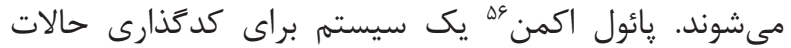

محيطى مى باشد.سيستم عصبى مركزى شامل مغز ونخاع مُ مي باشد.

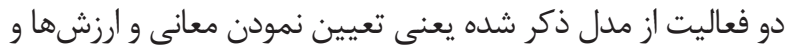

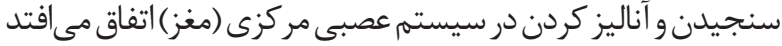

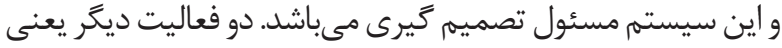

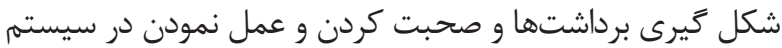

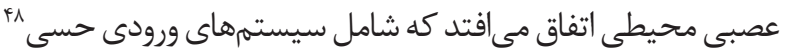

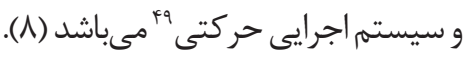

سيستم عصبى مر كزى و محيطى در معناى ساده تر، همان مغز و و

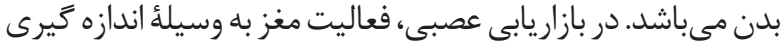

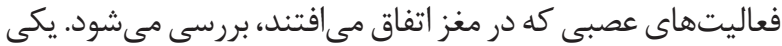

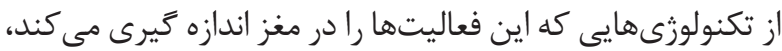

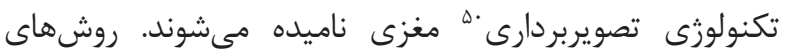

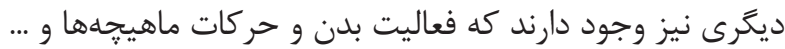

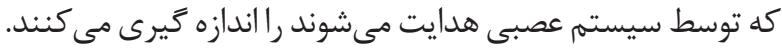

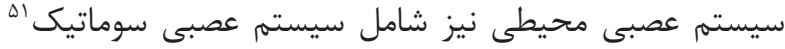

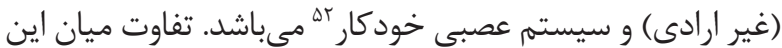

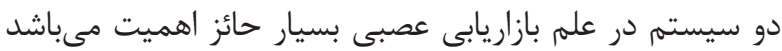

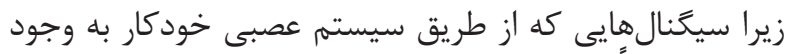

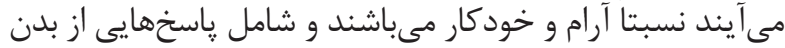

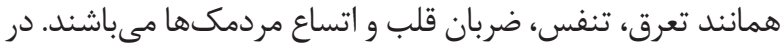

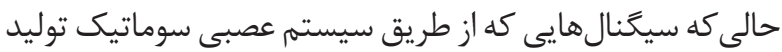

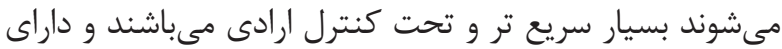

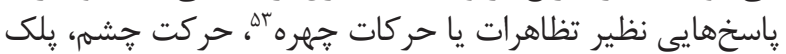
زدن و ياسخهاى رفتارى مى باشد. از جمله مقياسهايى كه مى توان با اندازه گيرى آنها به به فعاليتهاى

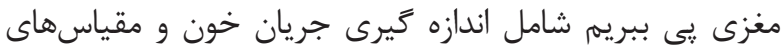

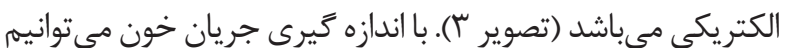

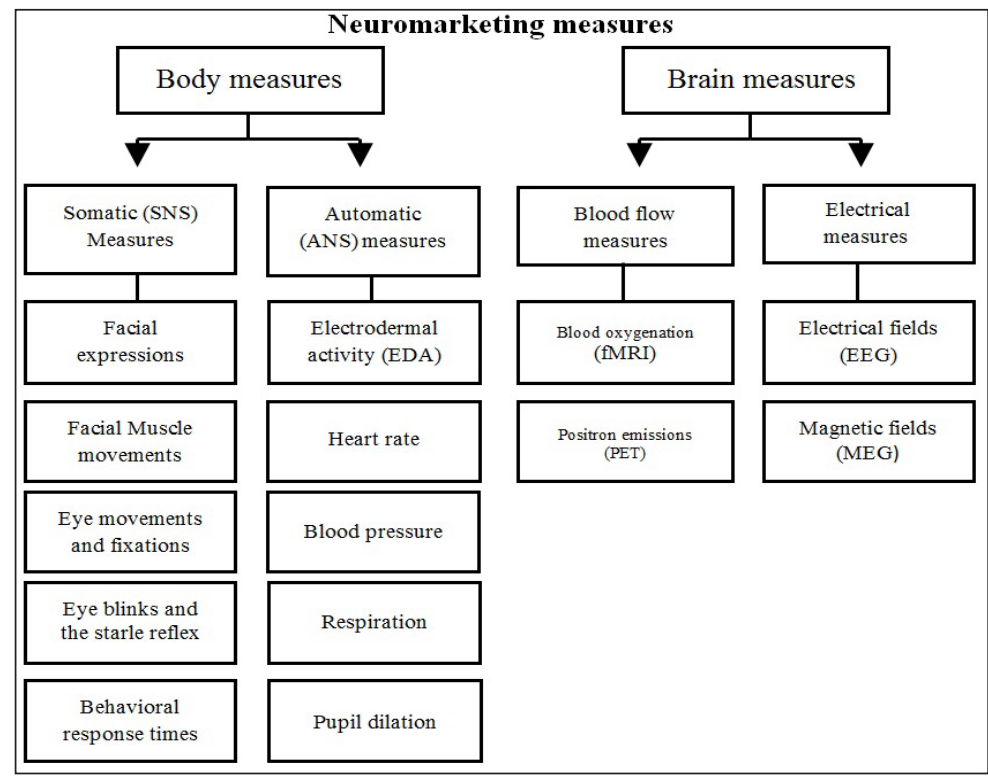

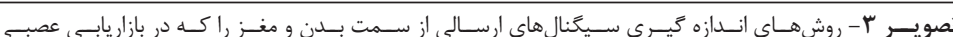

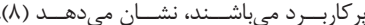

\footnotetext{
${ }^{47}$ Spinal cord

${ }^{48}$ Sensory input systems

${ }^{49}$ Motor execution system

${ }^{50}$ Neuroimaging technologies

${ }^{51}$ Somatic nervous system
}

${ }^{52}$ Autonomic nervous system

${ }^{53}$ Facial expressions

${ }^{54}$ Heart rate

${ }^{55}$ Charles Darwin

${ }^{56}$ Paul Ekman 


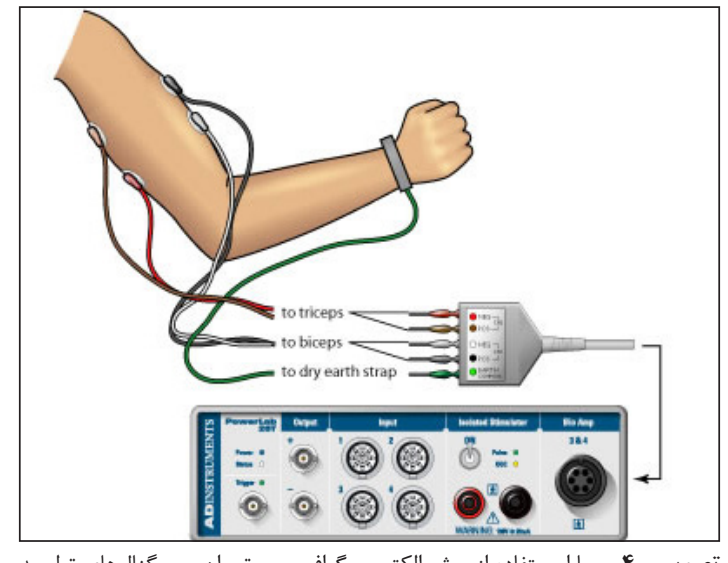

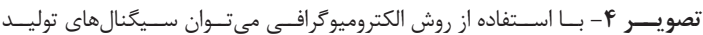

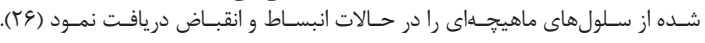

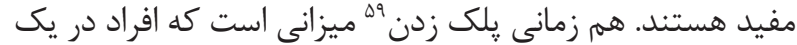

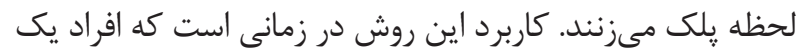

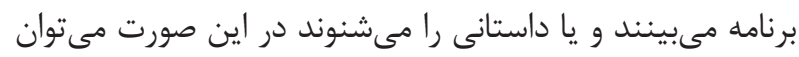

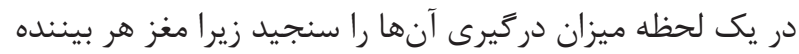

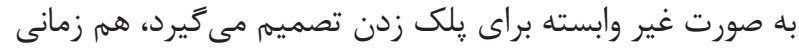

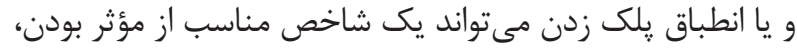

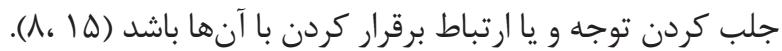

$$
\text { r- رديابى حركات جشم }
$$

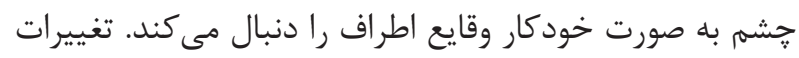

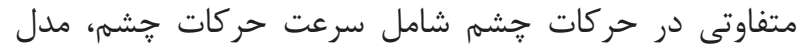

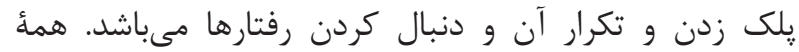

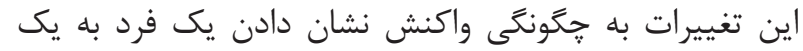

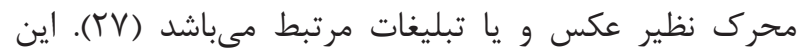

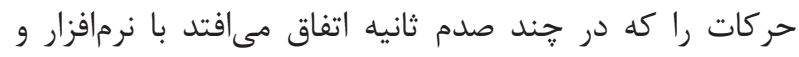

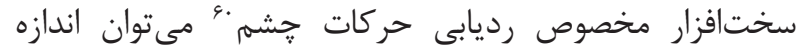

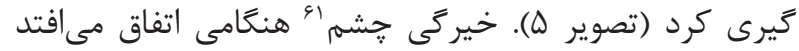

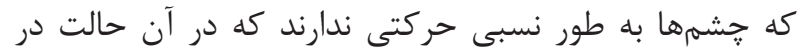

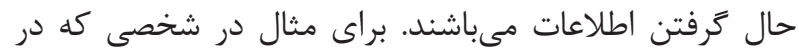

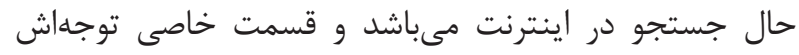

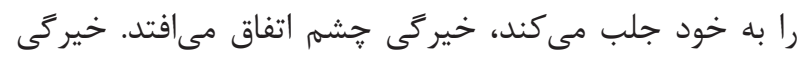

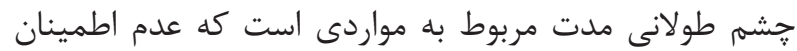

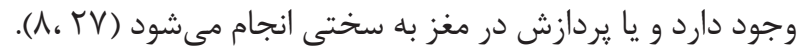

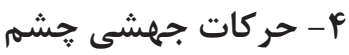

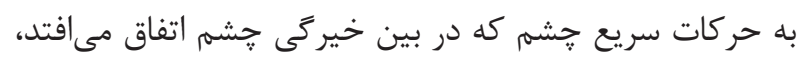

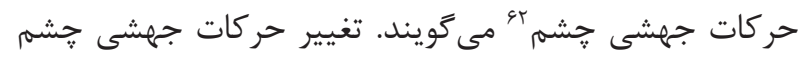

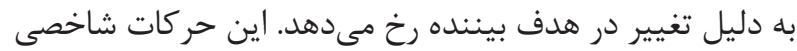

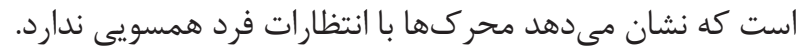

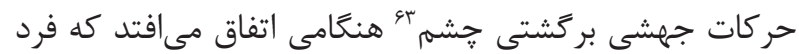

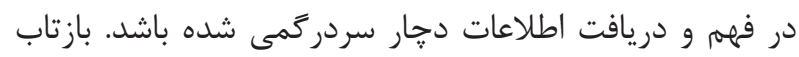

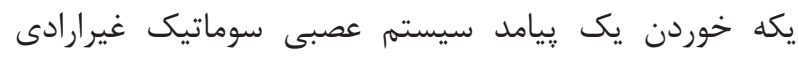

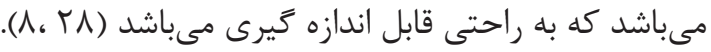

${ }^{57}$ Facial action coding system

${ }^{58}$ Electromyography (EMG)

${ }^{59}$ Eye blink

${ }^{60}$ Eye tracking
تجره كه بر روى حركات ماهيجههاى صورت انسان متمركز بوده

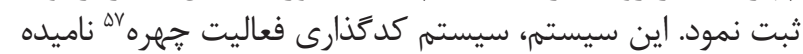

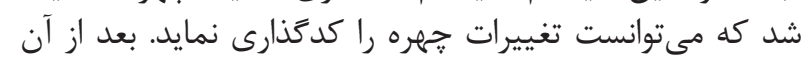

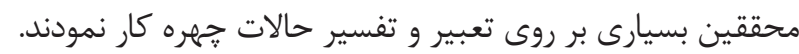

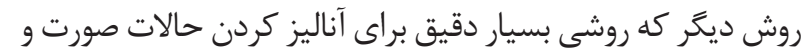

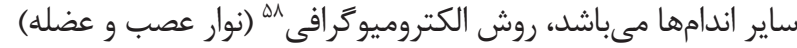

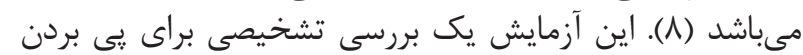

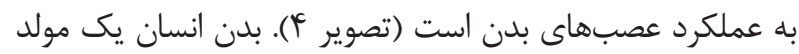

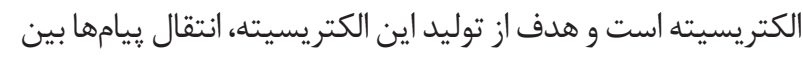

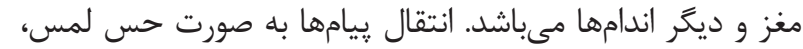

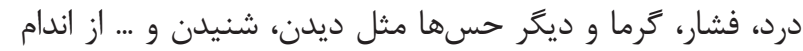

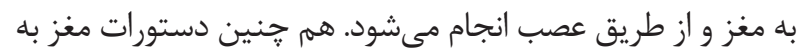

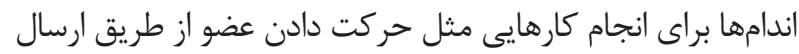

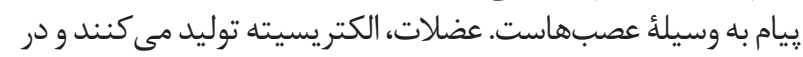

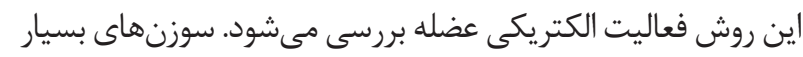

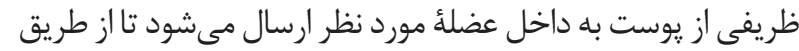

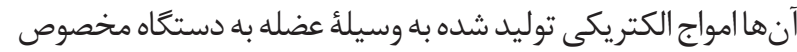

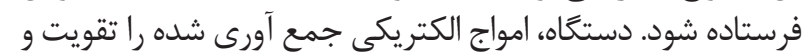

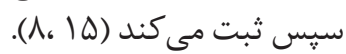

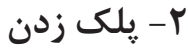

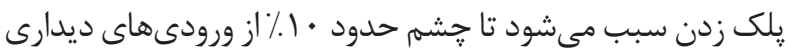

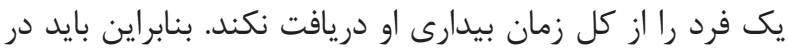

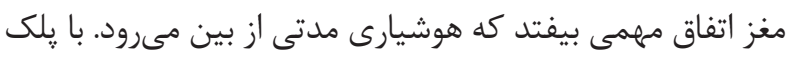

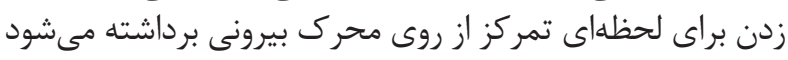

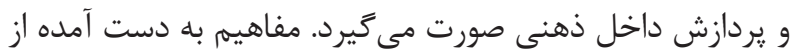

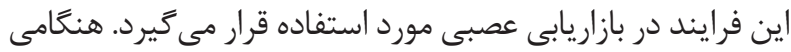

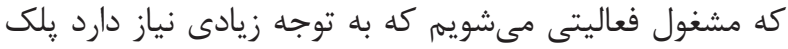

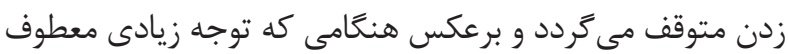

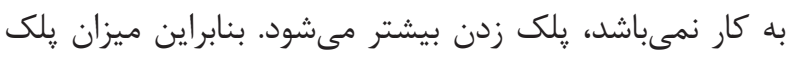

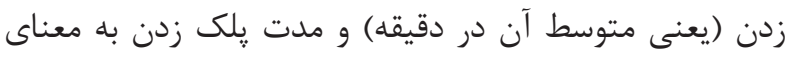

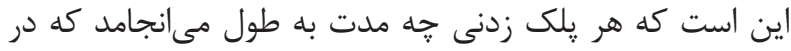
شاخصهايى كه به توجه و يا عدم توجه مرتبط مي مباشند، بسيار

${ }^{61}$ Eye fixation

${ }^{62}$ Saccade

${ }^{63}$ Regressive saccade 

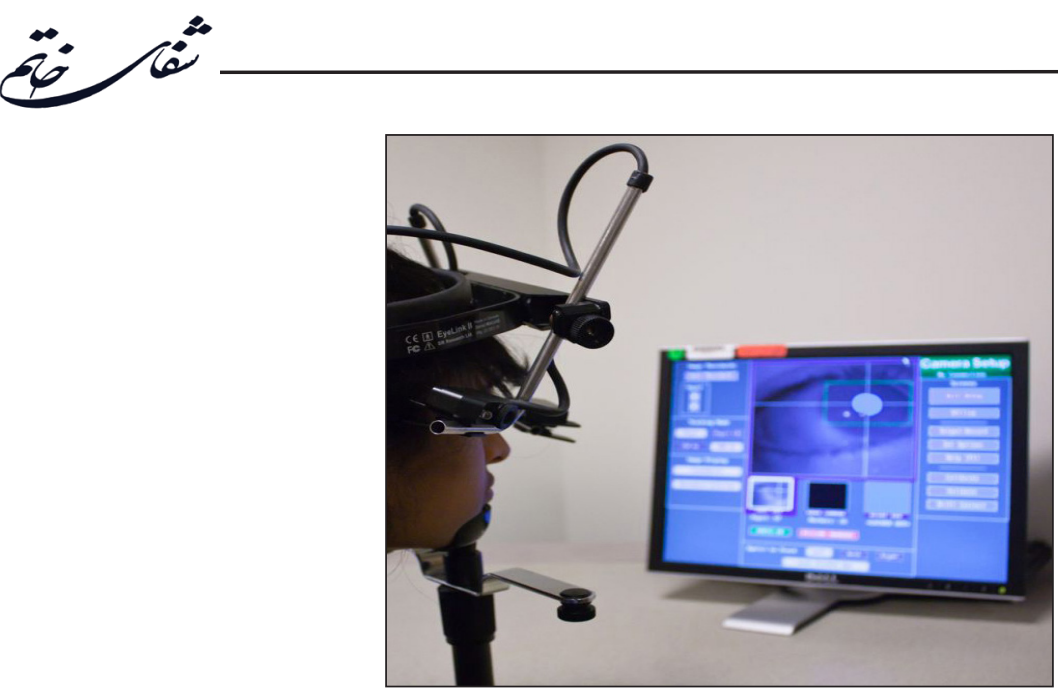

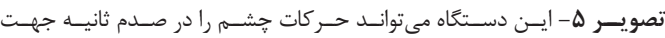

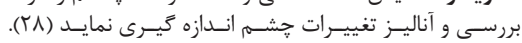

اطلاعات دريافتى مىدانند. بزرى شدن مردمكها يك مقياس

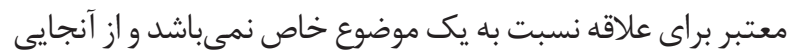

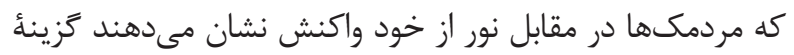

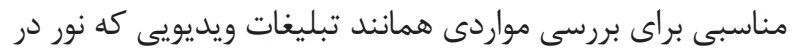

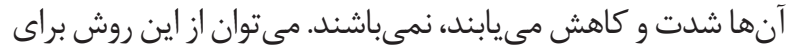

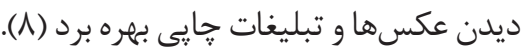

\section{V- فعاليت الكتريكى يوست يا الكترودرمال}

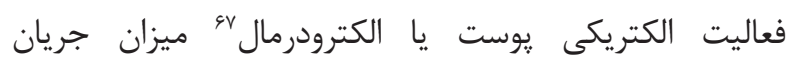

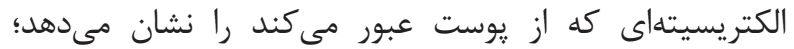

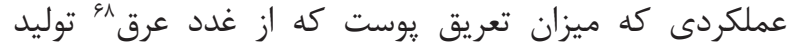

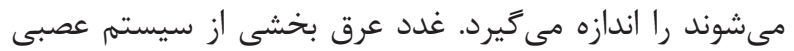

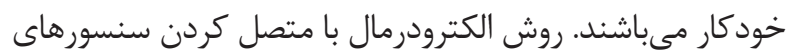

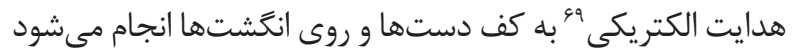

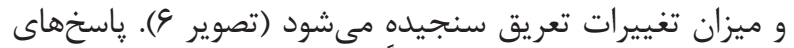

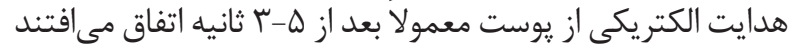

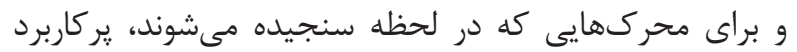

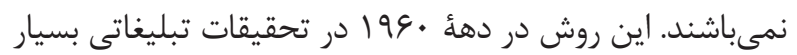

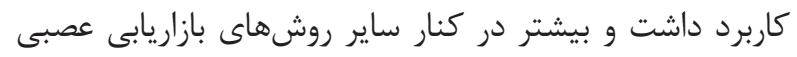

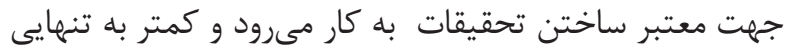

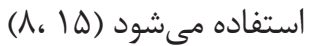

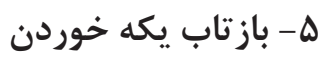

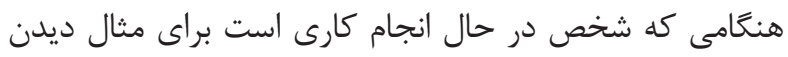

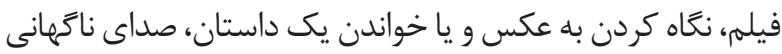

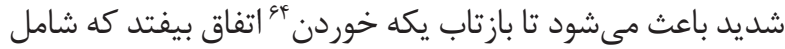

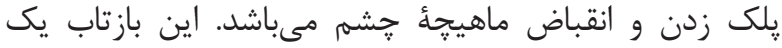

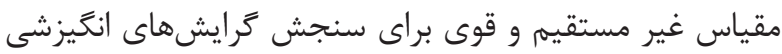

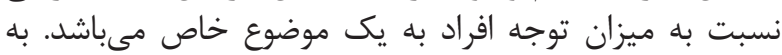

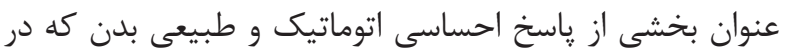

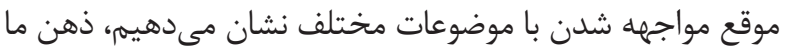

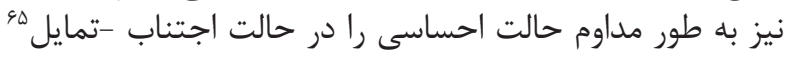

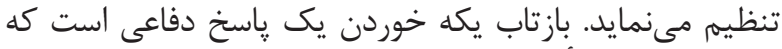

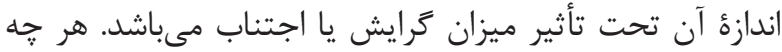

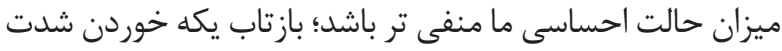

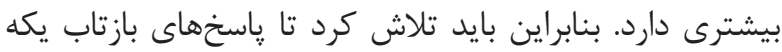

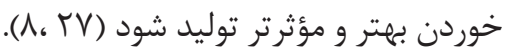

\section{9- اتساع مردمكها}

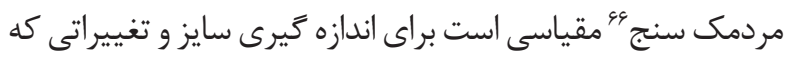

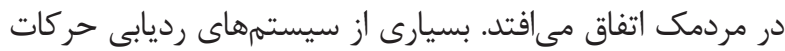

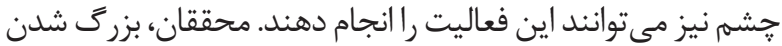

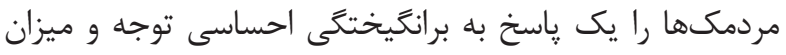

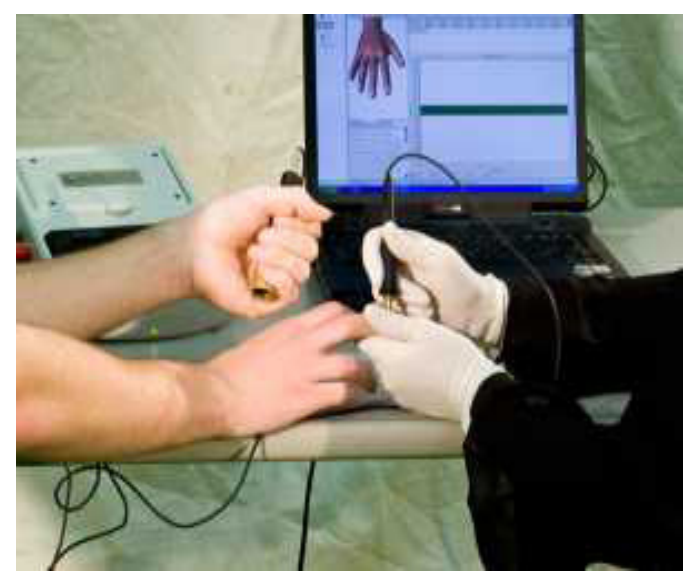

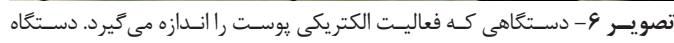

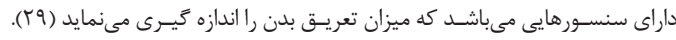

${ }^{64}$ Startle reflex

${ }^{65}$ Approach-avoidance

${ }^{66}$ Pupilometry

\footnotetext{
${ }^{67}$ Electrodermal activity

${ }^{68}$ Sweat glands

${ }^{69}$ Electrical conductance sensors
} 


$$
\text { 1- 1 - بررسى جريان خون در مغز }
$$

تكنولوزى هايى كه جهت بررسى جريان خون در مغز مورد استفاده

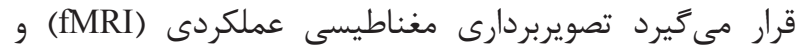

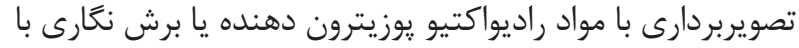

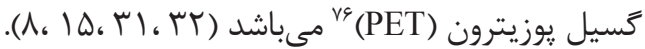

I-1 - (1ستخاه تصوير بردارى مغناطيسى عملكردى يا fMRI

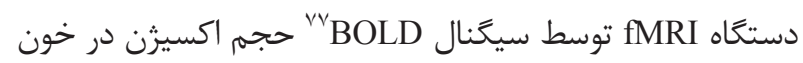

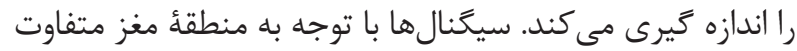

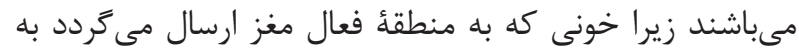

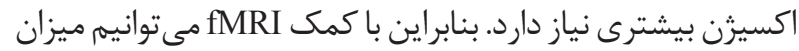

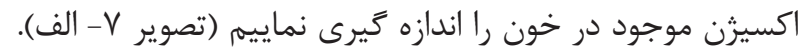

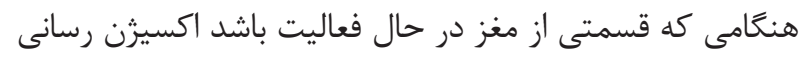

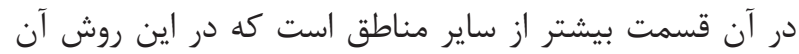

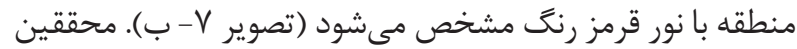

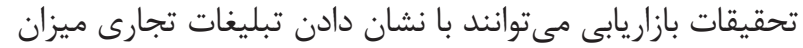

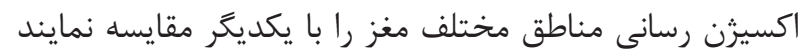

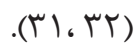

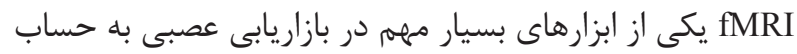

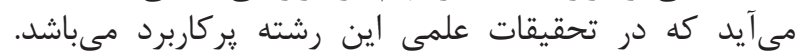

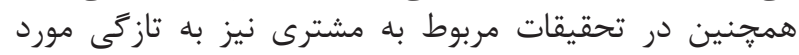

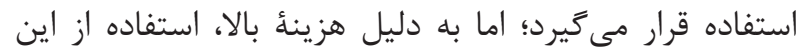

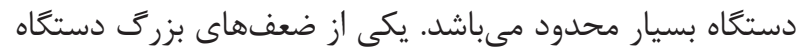

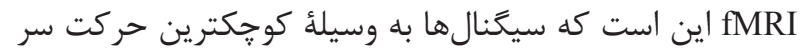

$$
\text { تغيير مى كنند (^). (^) }
$$

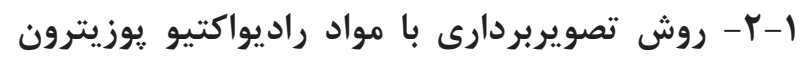

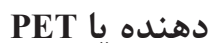

روش PET يكى از روشهاى تصويربردارى در يزشكى هستهاى

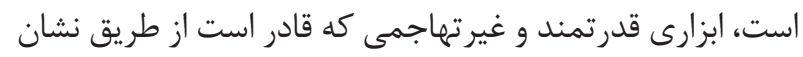

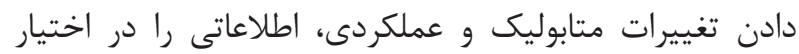

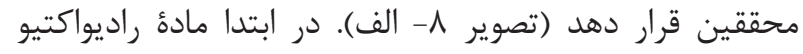
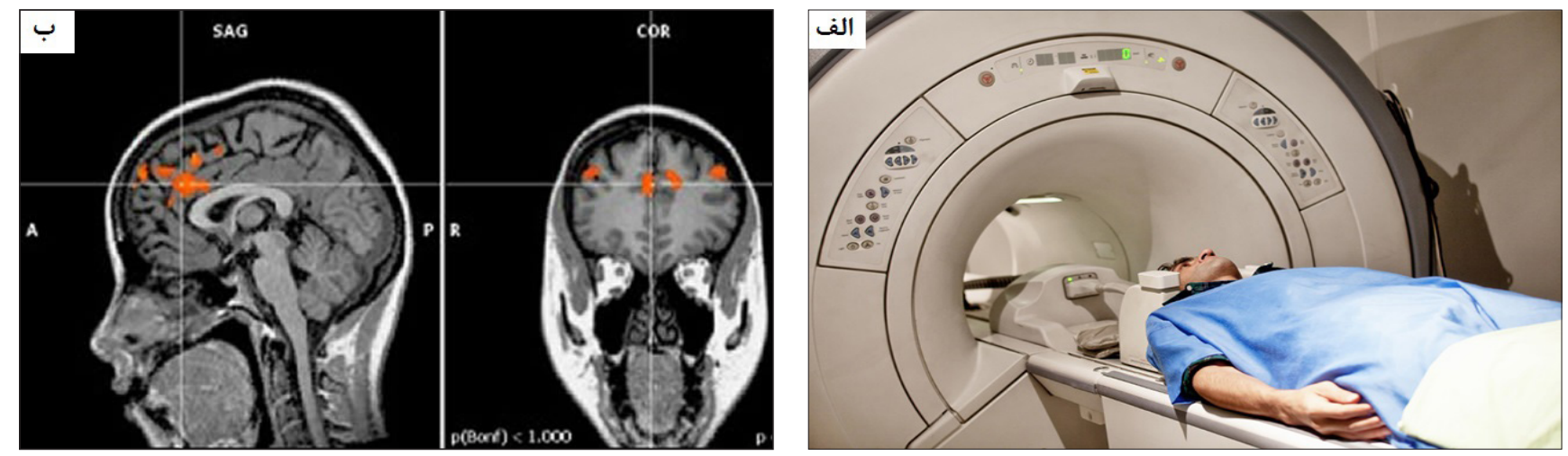

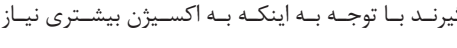

\footnotetext{
${ }^{70}$ Blood pressure

${ }^{71}$ Blood volume

${ }^{72}$ Pulse

${ }^{73}$ Vascular activity
}

1- ميزان تيش قلب، فشار خون و تنفس

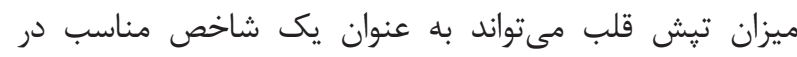

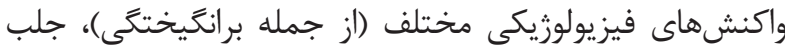

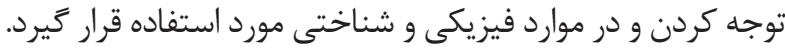

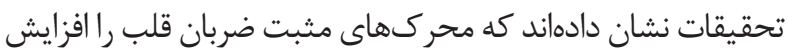

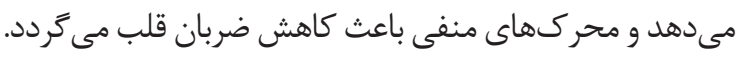

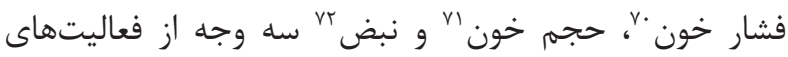

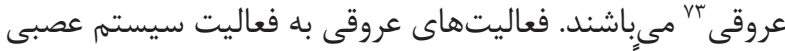

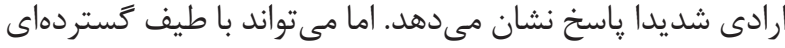

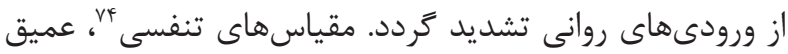

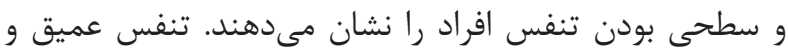

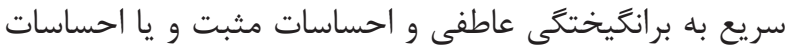

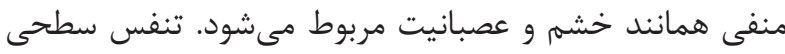

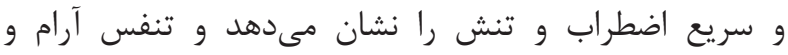

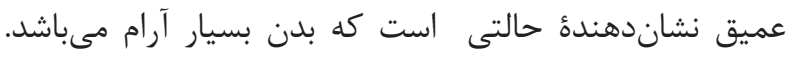

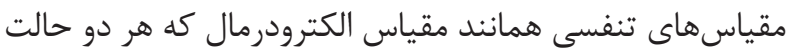

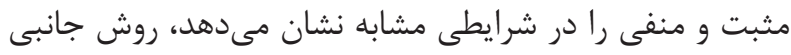

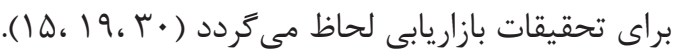

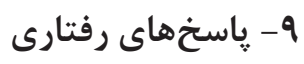

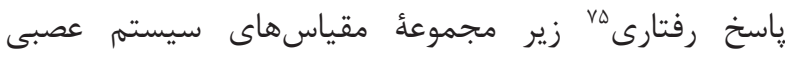

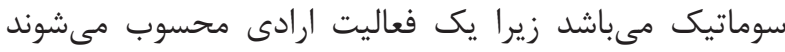

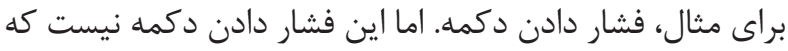

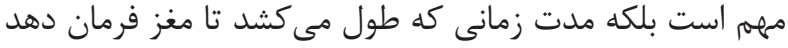

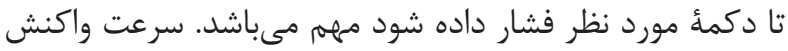

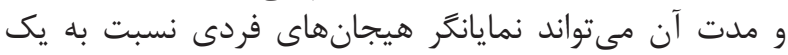

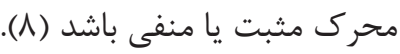
ب - سيخَنال هاى ارسال شده از مغز منز

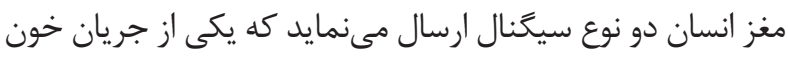

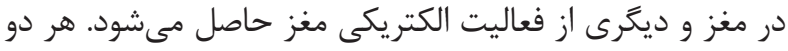

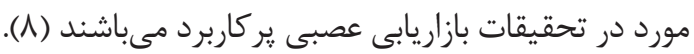



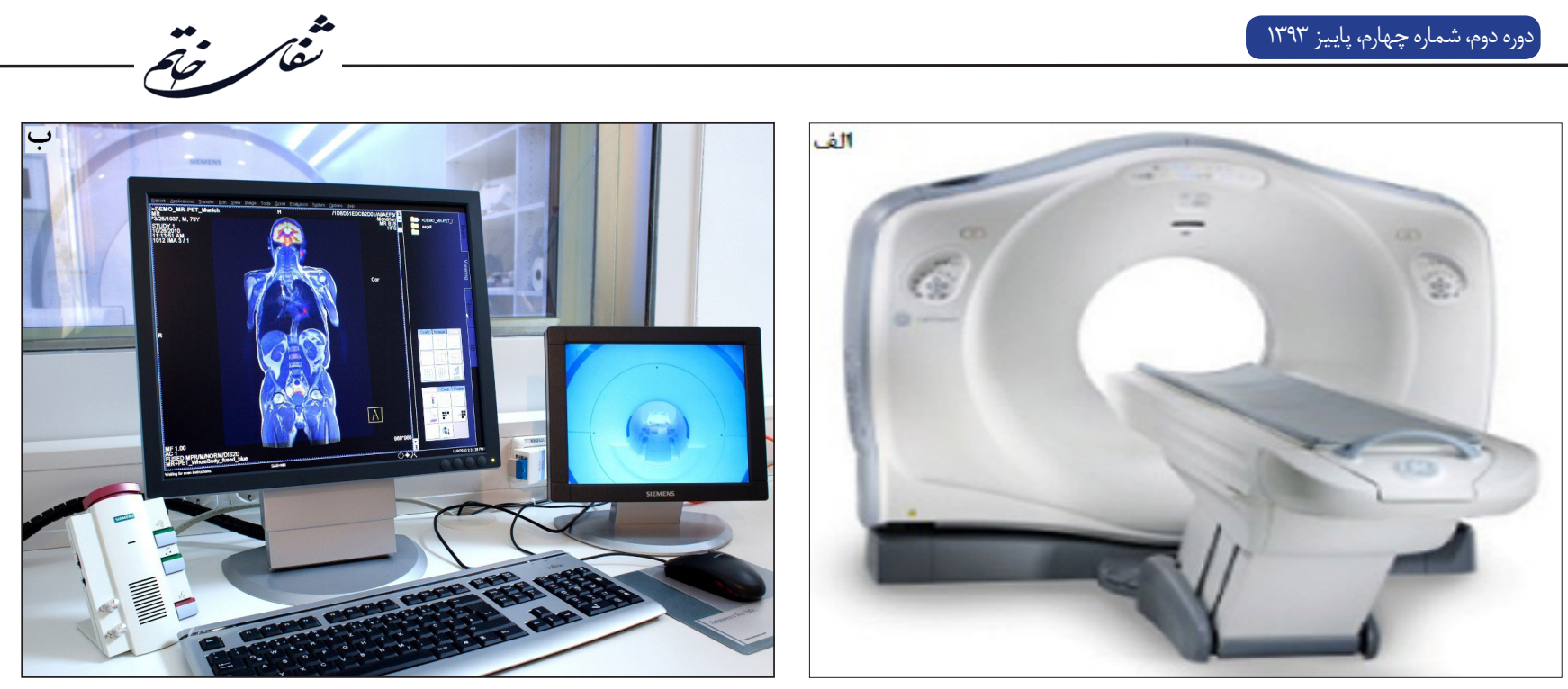

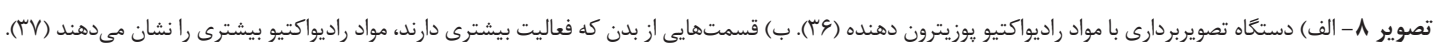

بسيار بالا در حد صدم ثانيه به ثبت فعاليت مغزى بيردازند.

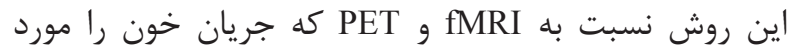

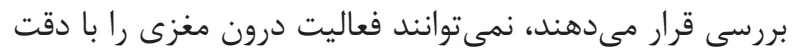

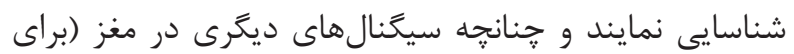

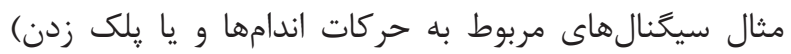
ايجاد شود، مىتوانند در ثبت سيكنال ها اختال التال ايجاد نمايند

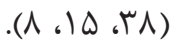

r-1 الكترو انسفالوكر افى يا نوار مغزى

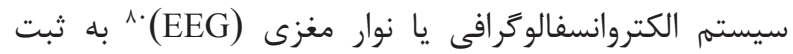

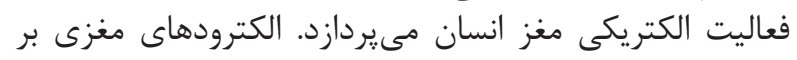

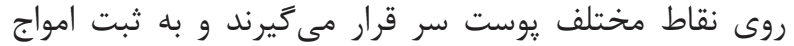

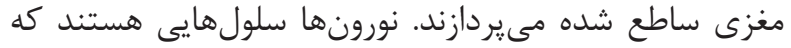

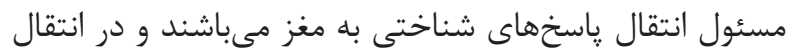

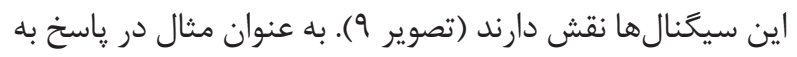

وارد بدن مىشود و به دنبال آن تصويربردارى صورت مى كيرد.

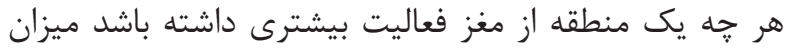

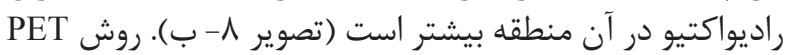

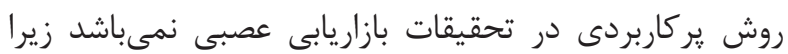

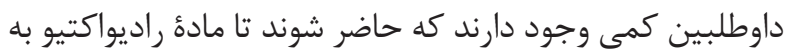

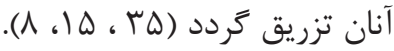

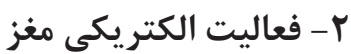

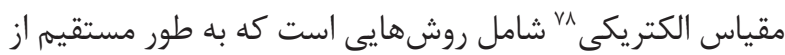

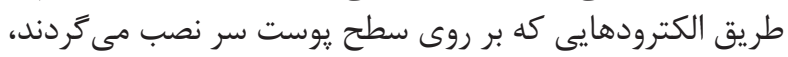

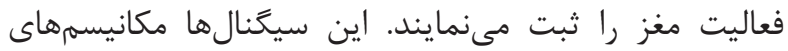

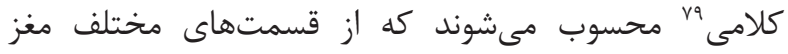

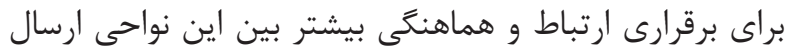

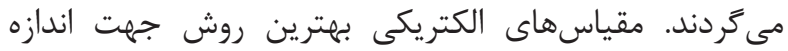

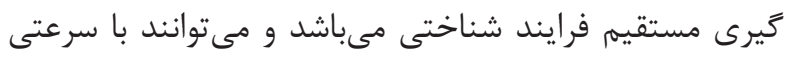

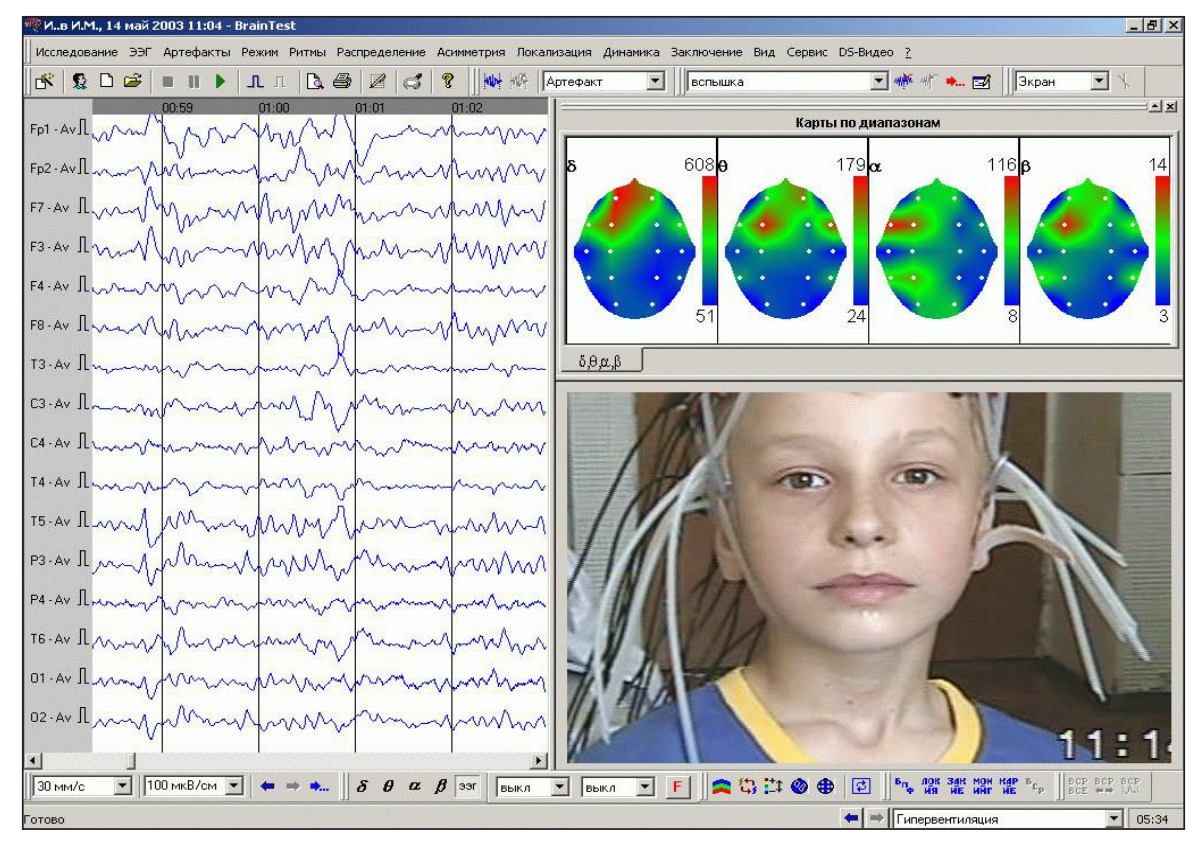

تصوير 9- الكتروانسفالوكرافى يا نوار مغزى به ثبت فعاليت الكتريكى مغز مىير دازد (9").

${ }^{78}$ Electrical measures

${ }^{79}$ Literal mechanism

${ }^{80}$ Electroencephalography (EEG) 


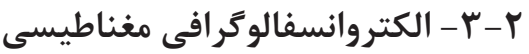

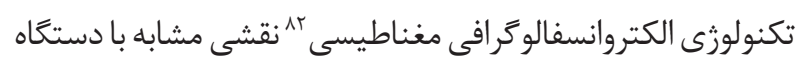

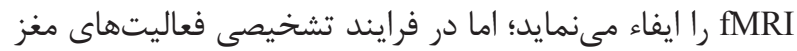

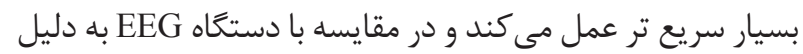

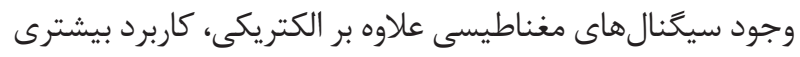

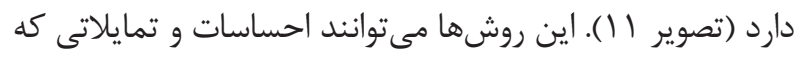

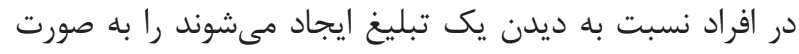

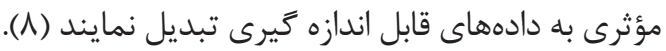

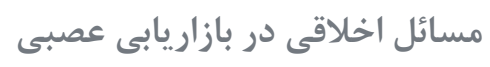

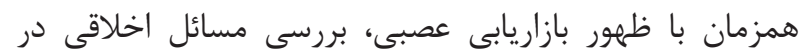

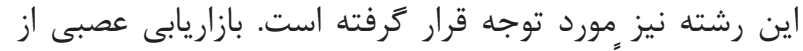

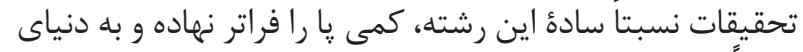

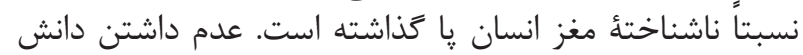

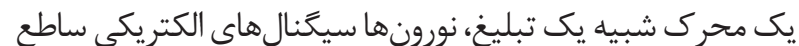

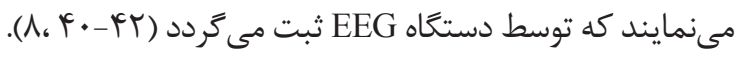

$$
\text { r-r }
$$

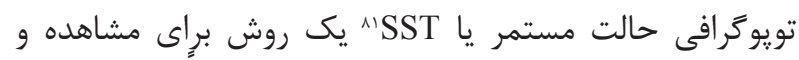

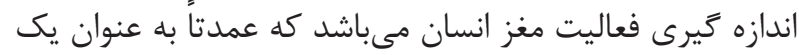

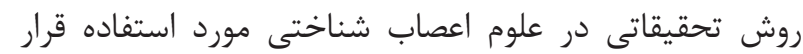

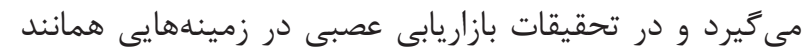

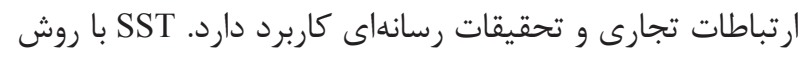

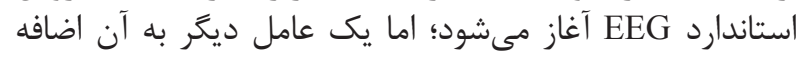

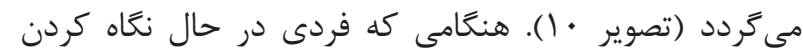

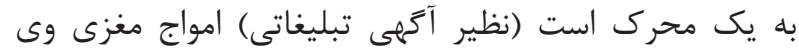

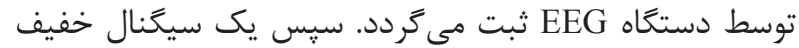

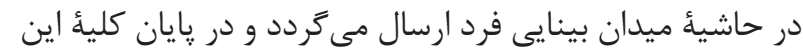

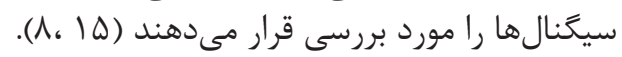
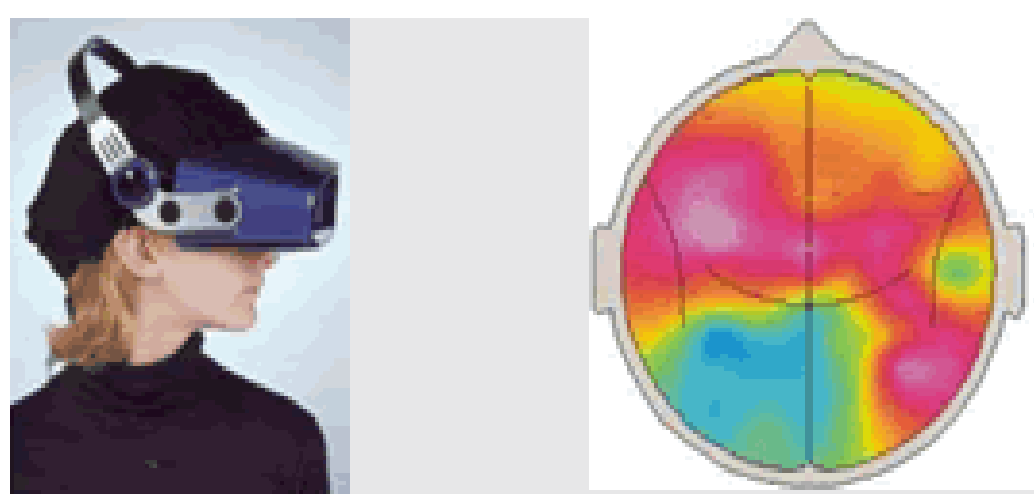

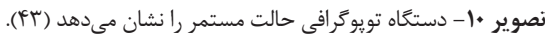

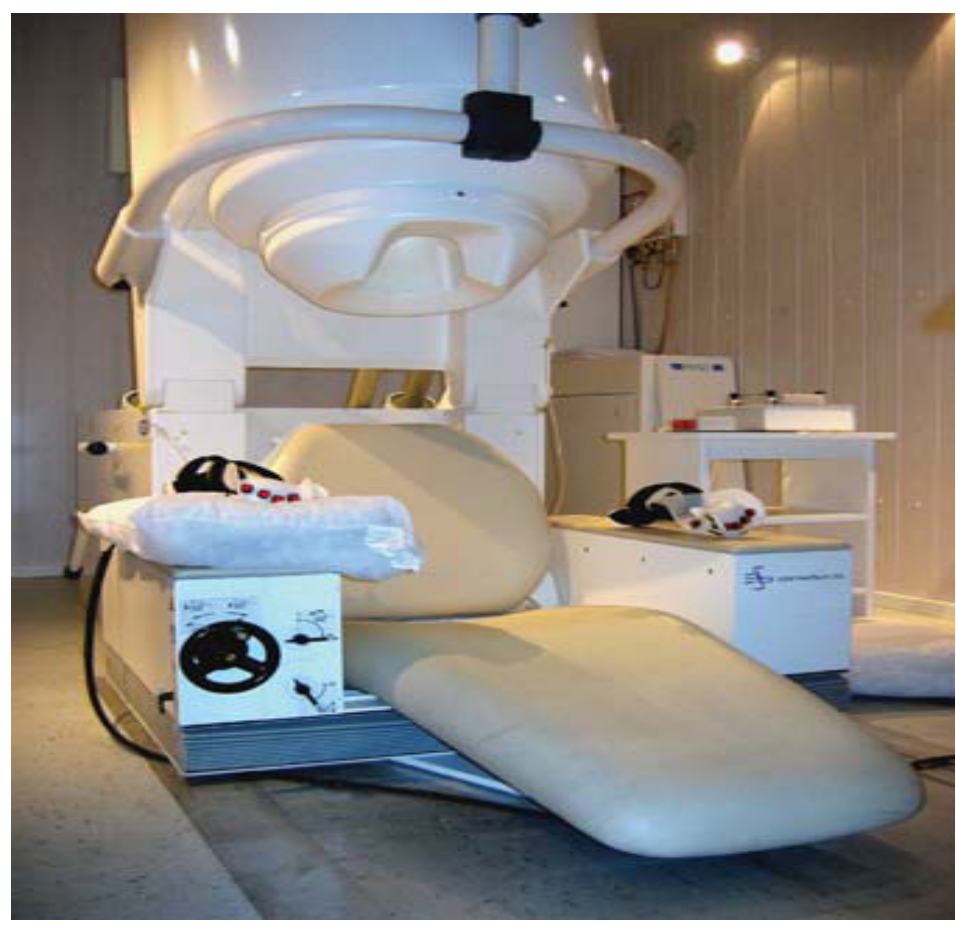

تصوير 11- دستًاه الكتروانسفالوكرافى مغناطيسى را نشان مىدهد (FY).

${ }^{81}$ Steady- state topography (SST) 
نتيجه گَيرى

در دهأ كذشته، در توسعه و بسط تكنولوزى در زمينههاى

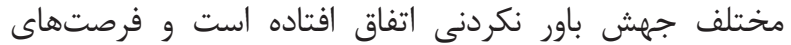
بىشمارى جهت يزروهش و تحقيق خلق شاور شده است؛ تحقيقات

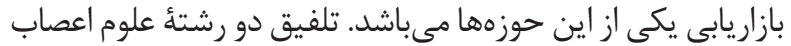

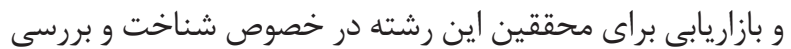

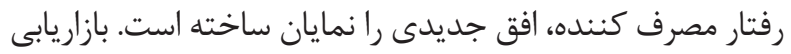

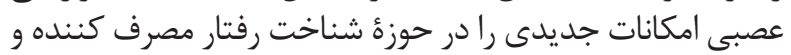

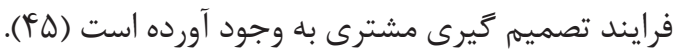
بازاريابى عصبى در קند سال كذشته مورد توجه بسيار زياد

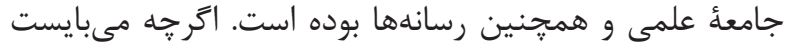

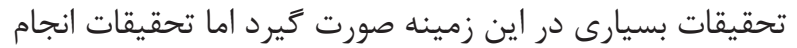

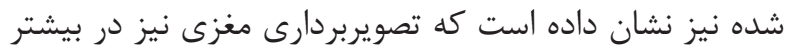

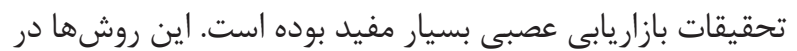

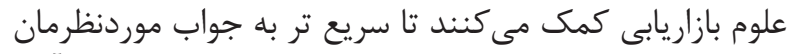

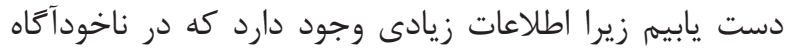

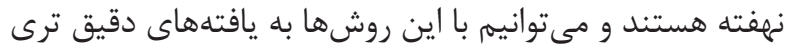
در خصوص توليد محصولات و ارائه تبليغات بازاريابى مؤثرتئر

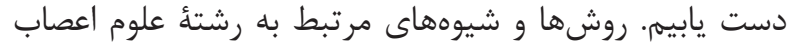

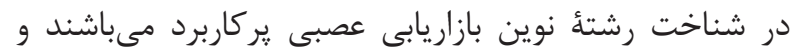

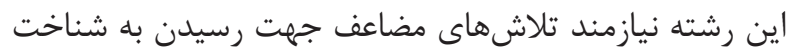

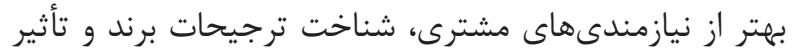

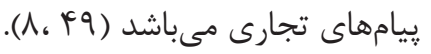

1. Fugate DL. Neuromarketing: A layman's look at neuroscience and its potential application to marketing practice. J Consum Mark. 2007; 24(7): 385-94.

2. Bagozzi RP, Gopinath M, Nyer PU. The role of emotions in marketing. J Acad Market Sci. 1999; 27(2): 184-206.

3. Vlasceanu S. Neuromarketing and evaluation of cognitive and emotional responses of consumers to marketing stimuli. Procedia Soc Behav Sci. 2014; 127: 753-7.

4. Blakeslee S. If you have a 'buy button' in your brain, what pushes it? The New York Times. 2004; $19^{\text {th }}$.

5. Karmarkar U. Note on Neuromarketing. Harvard Business School Marketing Unit Case. 2011; 512-031.

6. Veronica B. Brief history of neuromarketing. J Bert Rus. 2009; 119-21.

7. Hammou KA, Galib MH, Melloul J. The Contributions of Neuromarketing in Marketing Research. Journal of Management Research. 2013; 5(4): 20-33.

8. Genco SJ, Pohlmann AP, Steidl P. Neuromarketing
كافى عموم جامعه در خصوص بازاريابى عصبى اين تصوير را

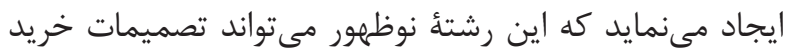

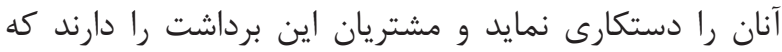

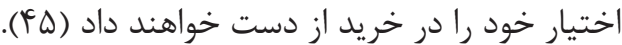

فرض اصلى كه در تحقيقات بازاريابى وجود دارد اين است كه

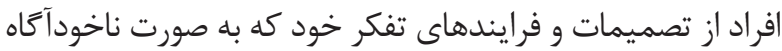

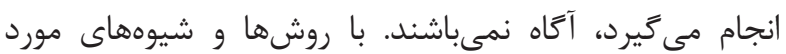

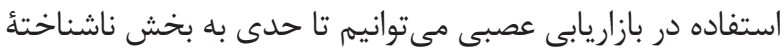

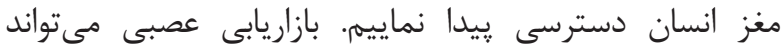

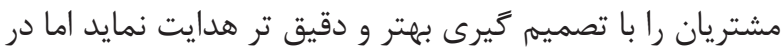

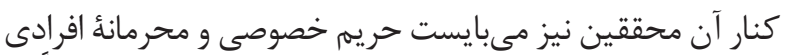

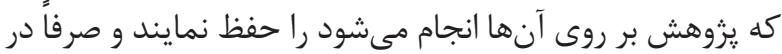

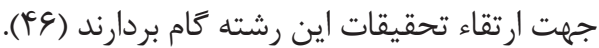

برخى از سازمانهاى حمايت كننده از مصرف كنند

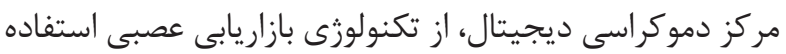

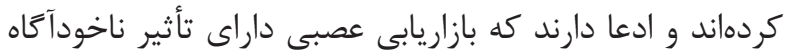

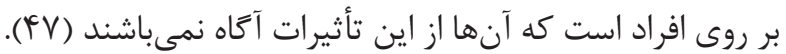

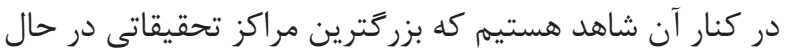

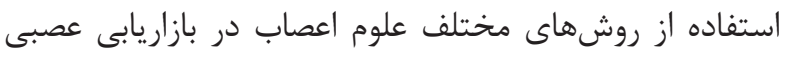

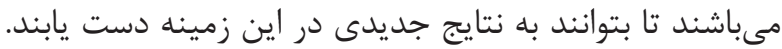

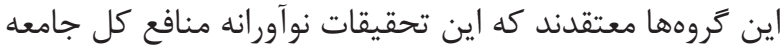

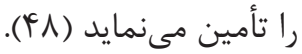

منابع

for dummies. $1^{\text {st }}$ ed. John Wiley and Sons Canada Ltd. 2013; p. 249-68.

9. Morin C. Neuromarketing: the new science of consumer behavior. Symposium: consumer culture in global perspective. Society. 2011; 48: 131-5.

10. Kable JW. The cognitive neuroscience toolkit for the neuroeconomist: A functional overview. J Neurosci Psychol Econ. 2011; 4(2): 63-84.

11. Plessis ED. The branded mind: What neuroscience really tells us about the puzzle of the brain and the brand? $1^{\text {st }}$ ed. Millward Brown. 2011; p. 23-40.

12. Deragi P. Neuromarketing: Theory and practice. $2^{\text {nd }}$ ed. Marketing publication.

13. Dargi P. Neuromarketing history. http://neuromarketing. ir/history/.

14. Dapkevičius A, Melnikas B. Influence of price and quality to customer satisfaction: neuromarketing approach. Science future of Lithuania. 2009; 1(3): 17-20.

15. Ben Naser L. Neuroscience techniques and the priming processes significance to neuromarketing 
advertising. ESJ. 2014; 1: 255-67.

16. http://www.yourselfseries.com/teens/topic/anatomy -101/your-nervous-system-the-brain.

17. Zurawicki L. Neuromarketing exploring the brain of the consumer. $2010^{\text {th }}$ ed. Springer. 2010.

18. Shaw EH, Jones DGB. A history of schools of marketing thought. Market Theory. 2005; 5(3): 239-81.

19. Calvert GA, Thensen T. Multisensory integration: methodological approaches and emerging principles in the human brain. J Physiol Paris. 2014; 98: 191-205.

20. Lee K, Lasana T. Harris How social cognition can inform social decision making Victoria. Front Neurosci. 2013; 7: 259.

21. Shadlen MN, Kiani R. Decision making as a window on cognition. Neuron. 2013; 80(3): 791-806.

22. Kahneman D, Tversky A. Choices, values and frames. American psychologist. 1984; 39(4): 341-50.

23. Kahneman D. Thinking, fast and slow. $1^{\text {st }}$ ed. Farrar, Straus and Giroux; Reprint edition. 2011; p. 19-97.

24. Kahneman D. A perspective on judgment and choice. Am Psychol. 2003; 58: 697-720.

25. Tversky A, Kahneman D. Judgment under uncertainty: Heuristics and biases. Science. 1974; 185(4157): 1124-31.

26. http://www.medchrome.com/basic-science/pathology /electromyography.

27. Duchowski A. Eye tracking methodology: Theory and practice. $2^{\text {nd }}$ ed. Springer. 2007.

28. http://www.massgeneral.org/psychiatry/research/ neuroimaging_equipment.aspx.

29. http://www.cornerstonehealth.ca/how-we-can-help/ electrodermal-screening.

30. Touhami ZO, Benlafkih L, Jiddane M, Cherrah Y, El-Malki HO, Benomar A. Neuromarketing: Where marketing and neuroscience meet. African Journal of Business Management. 2011; 5(5): 1528-32.

31. Lee NJ, Senior C, Butler MJ, Fuchs R. The feasibility of neuroimaging methods in marketing research. Nature precedings. 2009. hdl: 10101/npre. 2009. 2836. 1

32. Ariely D, Berns G. Neuromarketing: the hope and hype of neuroimaging in business. Nature. 2010; 11(4): 284-92.
33. http://today.uconn.edu/blog/2014/01/fmri-machinewill-expand-research-capabilities/.

34. http://www.neuroscientificallychallenged.com/glossary / functional-magnetic-resonance-imaging-fmri.

35. Spiers HJ, Maguire EA. Spontaneous mentalizing during an interactive real world task: an fMRI study. Neuropsychologia. 2006; 44:1674-82.

36. http://www.penrosestfrancis.org/psf/specialties/imaging -and-radiology/low-dose-radiation-ct-scan/.

37. http://www.unyesil.com/saglik/simensin-yeni-mr-cihazi -siemens-biograph-mmr.

38. Zaltman G, Kosslyn SM. Neuroimaging as a marketing tool. USA Patent. 2000; 6: 319.

39. http://www.simetronsac.com/dx_eeg1.php.

40. Ambler T, Ioannides A, Rose S. Brands on the brain: neuro-images of advertising. Bus. Strategy Rev. 2000; 11: $17-30$.

41. Astolfi L. Neural basis for brain responses to TV commercials: a high-resolution EEG study. IEEE Trans Neural Syst Rehabil Eng. 2008; 16: 522-31.

42. Vecchiato G1, Astolfi L, De Vico Fallani F, Toppi J, Aloise F, Bez F, et al. On the use of EEG or MEG brain imaging tools in neuromarketing research. Comput Intell Neurosci. 2011; 2011: doi: 10.1155/2011/643489.

43. http://www.sutherlandsurvey.com/Column_pages/ Neuromarketing_whats_it_all_about.htm.

44. http://www.britannica.com/EBchecked/topic/1471021 /magnetoencephalography-MEG.

45. Arlauskaitė E. Ethical issues in neuromarketing. Msc thesis. Lund. Lund University, School of Economics and Brand Management Program. 2013.

46. Akbari M. An overview to neuromarketing and its application. ShefayeKhatam. 2013; 2(1): 75-84.

47. Singer N. Making ads that whisper to the brain. The New York Times. http://www.nytimes.com/2010/11/14/ business/14stream.html? r=0, viđeno

48. Ulman YI, Cakar T, Yildiz G. Ethical issues in neuromarketing: I consume, therefore I am. Sci Eng Ethics. doi 10.1007/s11948-014-9581-5. 2014.

49. CamererC, Loewenstein G, Prelec D. Neuroeconomics: How neuroscience can inform economics. JEL. 2005; 43: 9-64. 